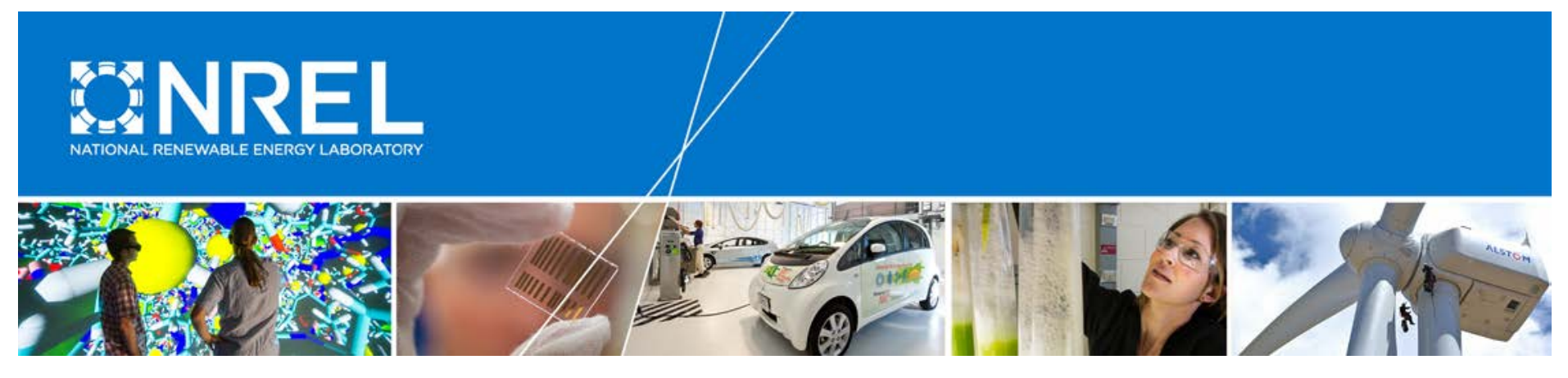

\title{
Field Guide for Testing Existing Photovoltaic Systems for Ground Faults and Installing Equipment to Mitigate Fire Hazards
}

William Brooks

Brooks Engineering

Vacaville, California

NREL Technical Monitor: Thomas Basso

NREL Task Leader: Michael Coddington

NREL is a national laboratory of the U.S. Department of Energy Office of Energy Efficiency \& Renewable Energy Operated by the Alliance for Sustainable Energy, LLC

This report is available at no cost from the National Renewable Energy Laboratory (NREL) at www.nrel.gov/publications.

\section{Subcontract Report}

NREL/SR-5D00-65050

October 2015

Contract No. DE-AC36-08GO28308 


\title{
Field Guide for Testing
} Existing Photovoltaic Systems for Ground Faults and Installing Equipment to Mitigate Fire Hazards

\author{
William Brooks
}

Brooks Engineering

Vacaville, California

NREL Technical Monitor: Thomas Basso

NREL Task Leader: Michael Coddington

Prepared under Subcontract No. LGN-3-23371-01

NREL is a national laboratory of the U.S. Department of Energy Office of Energy Efficiency \& Renewable Energy Operated by the Alliance for Sustainable Energy, LLC

This report is available at no cost from the National Renewable Energy Laboratory (NREL) at www.nrel.gov/publications.

National Renewable Energy Laboratory 15013 Denver West Parkway Golden, CO 80401

303-275-3000 • www.nrel.gov

\section{Subcontract Report}

NREL/SR-5D00-65050

October 2015

Contract No. DE-AC36-08GO28308 


\section{NOTICE}

This report was prepared as an account of work sponsored by an agency of the United States government. Neither the United States government nor any agency thereof, nor any of their employees, makes any warranty, express or implied, or assumes any legal liability or responsibility for the accuracy, completeness, or usefulness of any information, apparatus, product, or process disclosed, or represents that its use would not infringe privately owned rights. Reference herein to any specific commercial product, process, or service by trade name, trademark, manufacturer, or otherwise does not necessarily constitute or imply its endorsement, recommendation, or favoring by the United States government or any agency thereof. The views and opinions of authors expressed herein do not necessarily state or reflect those of the United States government or any agency thereof.

This report is available at no cost from the National Renewable Energy Laboratory (NREL) at www.nrel.gov/publications.

Available electronically at SciTech Connect http:/www.osti.gov/scitech

Available for a processing fee to U.S. Department of Energy and its contractors, in paper, from:

U.S. Department of Energy

Office of Scientific and Technical Information

P.O. Box 62

Oak Ridge, TN 37831-0062

OSTI http://www.osti.gov

Phone: 865.576.8401

Fax: 865.576.5728

Email: reports@osti.gov

Available for sale to the public, in paper, from:

U.S. Department of Commerce

National Technical Information Service

5301 Shawnee Road

Alexandria, VA 22312

NTIS http://www.ntis.gov

Phone: 800.553 .6847 or 703.605 .6000

Fax: 703.605.6900

Email: orders@ntis.gov 


\section{Nomenclature}

ac

$\mathrm{dc}$

NEC

OCPD

PPE

PV

$\mathrm{RCM}$

$\mathrm{V}_{\mathrm{oc}}$ alternating current

direct current

National Electrical Code

overcurrent protection device

personal protective equipment

photovoltaic

residual current monitor

open circuit voltage 


\section{Executive Summary}

Experience from the field suggests that ground faults and arc faults are the two most common reasons for fires in photovoltaic (PV) arrays; methods are available that can mitigate the hazards. This report provides field procedures for testing PV arrays for ground faults, and for implementing high-resolution ground fault and arc fault detectors in existing and new PV system designs.

Recent research done by the Solar America Board for Codes and Standards has shown that some PV system ground faults go undetected, which can lead to fires in PV arrays [1,2,3,4]. These undetected faults have been termed blind spots in the ground fault detection circuits used in most U.S. PV installations. These blind spots can be effectively eliminated by detection systems that monitor ground current at much higher resolution than is currently required. Arc fault detectors are now available that can detect and remove series arc faults as required by the 2011 National Electrical Code [5].

The combination of good maintenance procedures, high-resolution ground fault detectors, and arc fault detectors effectively addresses fire hazards in existing and new PV system installations. Moving forward, new system designs and construction should incorporate these features, because the cost of retrofitting is considerably higher than having the features initially installed.

Note: this report updates previous report of same title (SR-5D00-61018). 


\section{Contents}

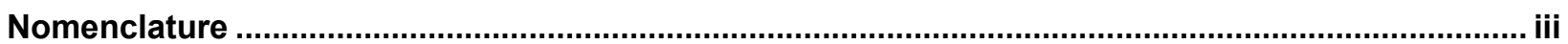

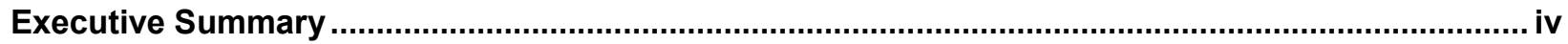

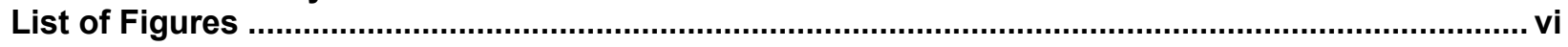

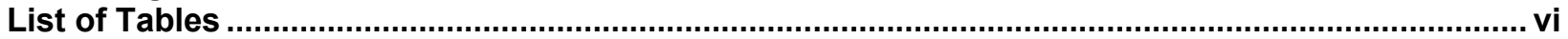

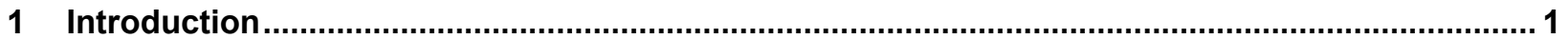

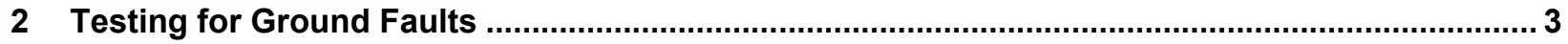

2.1 Testing Photovoltaic Systems With Indicated Ground Faults ..................................................... 3

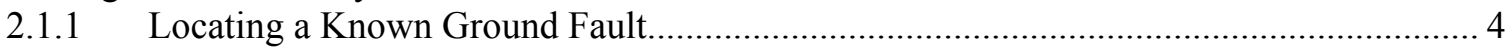

3 Testing Photovoltaic Systems With No Known Ground Faults ................................................ 9

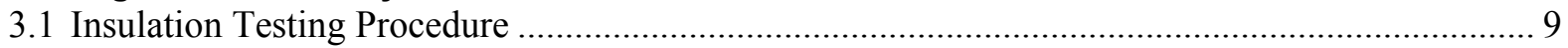

3.2 Field Procedure ........................................................................................................... 9

3.2.1 Phase 5: Testing the Whole Array at the Photovoltaic Output Circuit Combiner .......... 10

3.2.2 Phase 6: Testing Subarray at Individual Source Circuit Combiners .............................. 11

4 Retrofitting Existing Photovoltaic Systems With High-Resolution Ground Fault Detectors ..... 13

4.1 Installing a Residual Current Monitor on a Photovoltaic Array With a Large Inverter................. 13

4.1.1 Selecting and Installing the Appropriate Residual Current Monitor............................. 15

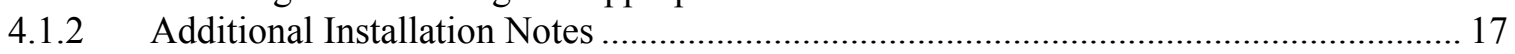

5 Finding Arc-Fault Failure Locations in a PV Array ................................................................ 19

6 Retrofitting Existing Photovoltaic Systems With Arc Fault Detectors ...................................... 20

6.1 Cost-Effective Ways To Implement Arc Fault Detectors on Larger Inverters ............................ 20

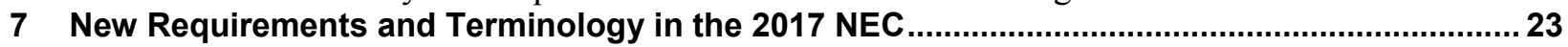

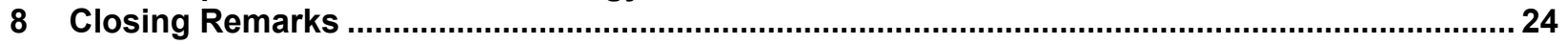

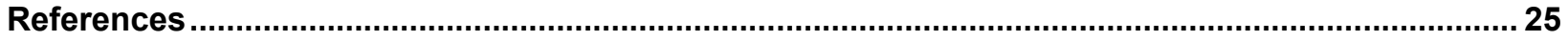

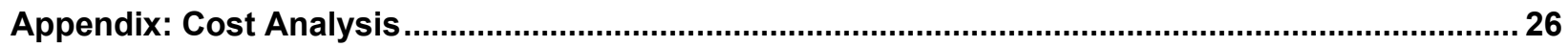




\section{List of Figures}

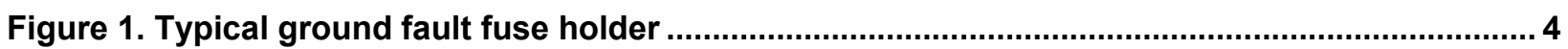

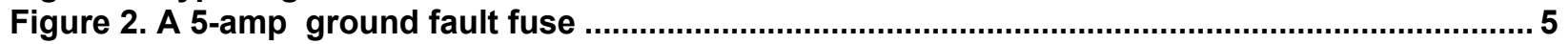

Figure 3. PV array diagram with disconnects at source and output circuit combiners .................... 6

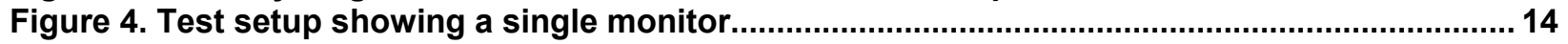

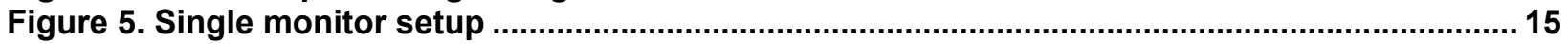

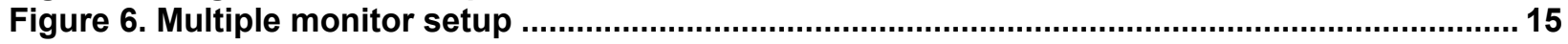

Figure 7. Multiple current transducers in PV output circuit combiner ......................................... 17

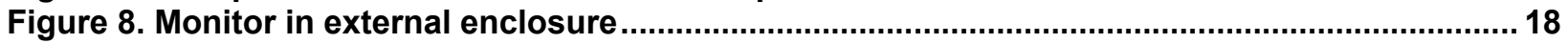

Figure 9. PV output circuit combiner equipped with residual current monitor................................ 18

Figure 10. Single arc fault detector for the whole system .............................................................. 21

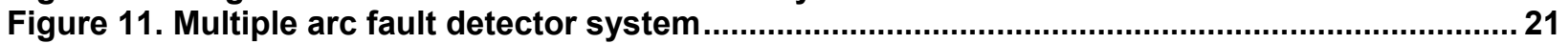

Figure 12. Source circuit arc fault detector system ................................................................... 22

\section{List of Tables}

Table 1. UL 1741 Ground Fault Detection Specifications Versus Inverter DC Rating ....................... 3 


\section{Introduction}

The primary audience for this guide includes field technicians who work on photovoltaic (PV) systems of all sizes and generation capacities. The guide also provides an educational resource for all stakeholders involved in PV system ownership (owners, financiers, insurance providers, etc.) of potential hazards and the need for equipment retrofit to mitigate these hazards. Proper work practices while working on systems with and without direct current (dc) ground faults are critical for safety and to accurately diagnose system problems. Dc ground faults in PV arrays are among the most hazardous electrical problems that can occur in a PV array and should be approached carefully according to the best safety practices. PV systems, and especially ground faults, are hazardous because of lethal voltages; ground faults are also hazardous to property because they can start fires. All field and testing procedures recommended in this guide are intended for experienced field technicians who are qualified and authorized to perform the work. The definition of qualified personnel in Article 100 of the National Electrical Code (NEC) is, "One who has skills and knowledge related to the construction and operation of the electrical equipment and installations and has received safety training to recognize and avoid the hazards involved." The definition of authorized personnel for the purpose of this guide is, "One who has been granted permission to work on the PV system by the system owner."

This guide focuses on typical PV systems installed in the United States over the past 12 years. The distinguishing "typical" feature for this guide is that a typical system has a current-carrying conductor that is either solidly grounded with an unbroken grounding electrode conductor to a grounding electrode system or is functionally grounded through an overcurrent protection device (OCPD) to a grounding electrode system. Grounding of exposed metal surfaces likely to become energized, also known as equipment grounding, is a requirement for all electrical systems governed by the NEC. Other system topologies have also been implemented in the United States over the past several years. These include non-isolated inverter designs, often referred to as transformerless inverters, such as those implemented by manufacturers such as Advanced Energy, KACO new energy, Power-One, and SMA America. Systems with these types of inverters have more comprehensive ground-fault detection systems than the grounded systems that make up the larger number of installed systems in the United States. Although the methods and tools shown in this guide can be used for non-isolated systems, the guide does not focus on those systems.

This guide includes the following major sections:

- Section 2: Testing for Ground Faults deals with proper techniques to address ground faults in arrays having indicated ground faults. Ground fault detectors are located in nearly all currently manufactured PV inverters.

- Section 3: Testing Photovoltaic Systems With No Known Ground Faults deals with proper techniques for testing arrays with no known ground faults. These techniques are similar to those in Section 2; however, additional equipment and methods may be needed to detect faults that do not appear in typical ground fault detection systems.

- Section 4: Retrofitting Existing Photovoltaic Systems With High-Resolution Ground Fault Detectors discusses mitigation methods, based on high-resolution detection of very low-level ground faults. These methods will likely obviate the need to perform the testing 
required for systems with no known ground faults, because high resolution methods can detect virtually all ground faults.

- Section 5: Finding Arc-Fault Failure Locations in a PV Array discusses current field testing practices and future potential tools for finding the location of arc faults after an arc fault detector is activated.

- Section 6: Retrofitting Existing Photovoltaic Systems With Arc Fault Detectors discusses mitigation methods for detecting and locating arc faults. The combination of highresolution ground-fault detection and arc-fault detection can effectively reduce the likelihood of fires caused by PV systems to levels comparable to or better than that of conventional alternating current (ac) electrical safety protection systems throughout the United States.

By improving the safety of PV system wiring to levels consistent with, or better than conventional ac systems, the solar PV industry can confidently operate as part of the U.S. electrical industry knowing they maintain adequate electrical safety. 


\section{Testing for Ground Faults}

\subsection{Testing Photovoltaic Systems With Indicated Ground Faults}

Whenever a ground fault detector indicates a ground fault, field technicians must assume that conductors or equipment are damaged and need repair. Unless extensive field testing shows that no fault exists, the only safe assumption is that damage has occurred and there is an existing electrical hazard to the system and repair is required. False detections of ground faults are not unheard of, but are far fewer than properly detected faults. Intermittent ground faults are the most problematic to find, because testing may not resolve their location. In this case, field technicians may make the false assumption that no fault exists and give the system a clean bill of health, only to have the fault resurface later. These intermittent faults underline the need for fault detectors that are permanently installed and are highly sensitive so faults can be identified when they occur and be properly corrected.

A ground fault can result from a failure of the insulation that isolates current-carrying conductors from contact with grounded, conductive surfaces. For grounded systems, a ground fault will result in unintended current in the equipment grounding conductors and grounded equipment. This current depends on the voltage at the ground fault location and the impedance in the unintended circuit. Previously installed grounded systems with ground fault detectors in the inverter are required to detect ground faults of 1-5 amps, depending on the power rating of the inverter. Table 1 shows the specified maximum ground fault OCPD sizes based on inverter dc rating.

Table 1. UL 1741 [6] Ground Fault Detection Specifications Versus Inverter DC Rating

\begin{tabular}{ll}
\hline Inverter DC & $\begin{array}{l}\text { Maximum Ground Fault } \\
\text { Rating (kW) }\end{array}$ \\
\hline $0-25$ & 1 \\
\hline $25-50$ & 2 \\
\hline $50-100$ & 3 \\
\hline $100-250$ & 4 \\
\hline$>250$ & 5 \\
\hline
\end{tabular}

It is normal for PV systems to have small leakage currents flowing between the PV cells and ground. The magnitude of these currents depends on a variety of factors, including the size of the system, the amount of conductive surface in contact with circuits, the presence of conductive media (e.g., moisture), and damage to the integrity of the circuit. For PV arrays constructed with crystalline silicon modules, typical ground currents for properly operating residential systems are a few microamps; typical current flows for a 500-kW PV array are a few milliamps. Thin film array technologies may have leakage currents either less than or greater than those of crystalline array PV systems depending on their construction. Field technicians need to become familiar with the products that are being tested before they can assume that an abnormal ground current is flowing. Any ground currents exceeding those listed in Table 1 are abnormal and can be hazardous. However, a ground current as low as $100 \mathrm{~mA}$ can still indicate a severe fault on a grounded conductor. Since current standards may not require such low detection levels, better ground fault detection methods must therefore be retrofitted to many existing PV systems to prevent the potential for injury and property damage. 


\subsubsection{Locating a Known Ground Fault}

For a system with an indicated ground fault, the process of finding the ground fault can be quite simple, depending on whether the system has one series string as a source circuit or many source circuits. Large $500-\mathrm{kW}$ inverter systems may have 10 or more combiner boxes-each with 10 20 source circuits. A process of elimination must be used for these larger systems. If the fault cannot be found with the following procedure, the fault may be intermittent so Section 3 has procedures for testing systems with no obvious ground faults.

\subsubsection{Field Procedure}

Tools include:

- Personal protective equipment (PPE) rated for maximum system voltage (hand, head, etc.)

- Other PPE as necessary (eye, fall, etc.)

- Screwdriver or combiner box key if applicable

- Dc clamp-on ammeter.

DC Voltmeter

\section{$\triangle$ caution}

Throughout this document, the term "no current" is used. Dc clamp-on ammeters may not measure accurately below a few hundred milliamps. Currents below $500 \mathrm{~mA}$, while still being able to draw a brief arc, are not uncommon.

- Electrical tape

- System drawings - source circuit wiring diagram, disconnect locations

- Recording device (pen and paper, laptop, or tablet).

\subsubsection{Phase 1-Initial Testing}

1. Record the information shown on the display of the inverter or ground fault detector.

2. Confirm that the information on the display is indicative of a ground fault as compared to specifications in the product manual.

3. Consult any available information on the data acquisition system to determine when the system shutdown occurred (if the system is shut down).

4. After recording all available information with the equipment active, follow the installation manual instructions to disconnect all power sources to the inverter or ground fault detector. Apply lock-out, tag-out procedures, using approved devices to open

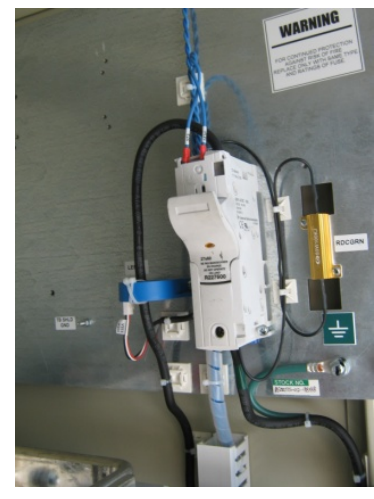

Figure 1. Typical ground fault fuse holder and secure all disconnecting means.

5. Allow at least 5 minutes for capacitors in the inverter to discharge (consult the inverter manual for minimum discharge time for capacitors). 
6. With proper PPE in place, test for voltage on the inverter side of the de disconnect to ensure the inverter has no hazardous voltage.

7. Test for current on the grounding circuit used by the ground fault detector.

8. For ground fault detectors using circuit breakers, observe and record whether the breaker is in the closed, tripped, or open position.

\subsubsection{Phase 2a—No Current in Grounding Circuit (with current, go to Phase 2b)}

If the grounding circuit has no current, open the fuse holder (Figure 1) to the ground fault fuse, or open the circuit breaker if the breaker is in the closed or tripped position.

1. For ground fault detectors using fuses (Figure 2), remove the fuse and note whether the fuse is blown. NOTE: Some fuses have indicator pins that contact a circuit in the holder when blown, and some fuses may still show some continuity even after being blown. Review the manufacturer's guidance on testing whether a fuse is good.

2. With the ground fault fuse holder or circuit breaker open, proceed to the first source circuit combiner box and start phase 3 of the testing (skip Phase 2b).

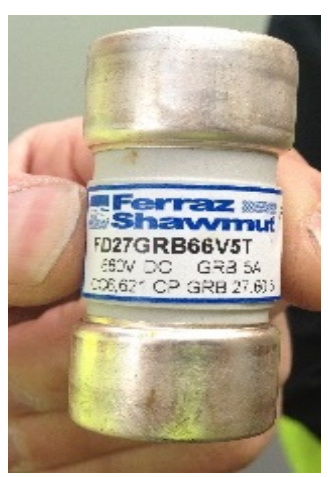

Figure 2. A 5-amp ground fault fuse

\section{DANGER}

For safety while testing a resolving ground-faults in a PV array, the PV system ground bond must be opened to prevent circuit paths through the system ground bond.

\subsubsection{Phase 2b-Current in Grounding Circuit}

\section{DANGER}

Larger three-phase inverters that predate 2005 may not have an OCPD in the ground fault detector, so large currents may be flowing.

\section{CAUTION}

Inverters with an OCPD in the ground fault detector may have a current in that device as high as the device rating or even higher. Be aware that previous service personnel may have installed higher rated fuses than those certified in the ground fault detector allowing even higher fault currents.

1. If the grounded circuit has a current, record the current level.

2. When current is present, the source of the current must be located and disabled. For systems with multiple combiner boxes and dc disconnecting means, open all the dc disconnects prior to opening the PV output circuit combiner box disconnects (often called a recombiner), (see Figure 3).

NOTE: This step will not eliminate the current flow to a fault, but it may reduce that current and it will prevent circulating currents that normally exist due to variations in the 
open circuit voltage $\left(\mathrm{V}_{\mathrm{oc}}\right)$ among combiner boxes in the array. (Safety Note: If no disconnects are installed between the PV source combiners and the PV output circuit combiner, this step is hazardous during daylight hours.)

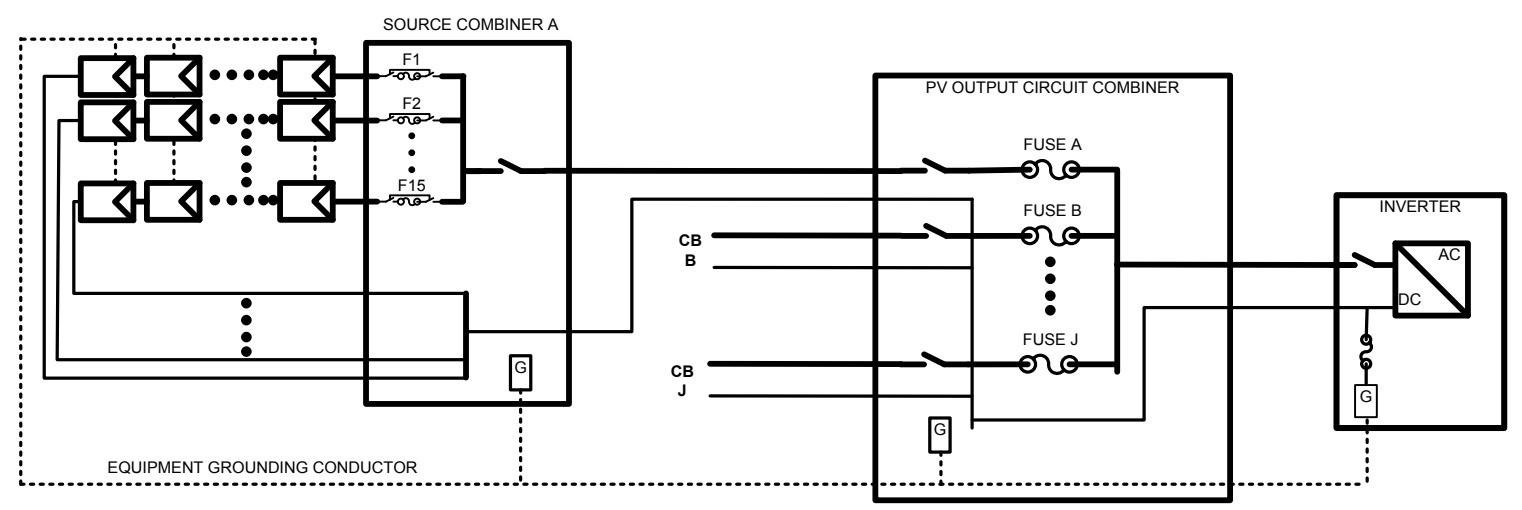

Figure 3. PV array diagram with disconnects at source and output circuit combiners

3. With all source circuit combiner and PV output circuit switches open, test the grounded conductor current at the PV output circuit combiner. The conductor with current on the grounded conductor that matches the current measured at the ground fault protector is the conductor with the fault. (Note: more than one circuit may have a grounded conductor fault, but this is unlikely.)

4. Proceed to the combiner box associated with the grounded conductor current and verify that the current is present in the combiner box's grounded output circuit conductor (Phase $3)$.

\subsubsection{Phase 3-Testing of Source Circuits at the Combiner Box}

1. At the selected source circuit combiner, test and record the ungrounded conductor current at each fuse holder (select the combiner in consecutive order if proceeding from Phase $2 \mathrm{a}$ or according to a faulted PV output circuit if proceeding from Phase 2b.)

2. Open all fuse holders in the combiner box connected to ungrounded conductors with current below 1 amp (usually only a few tenths of an amp in crystalline silicon arrays).

a. NOTE 1: Small currents flow in source circuit combiners because each string has a slightly different $\mathrm{V}_{\mathrm{oc}}$. The currents should be low and similar to one another.

b. NOTE 2: If all fuses have current because of a faulted string, wait until ground fault is cleared before opening any fuse holders. The faulted string is generally the string with the most current. Open both ends of the faulted string using appropriate PPE including insulated gloves and any necessary tool to release the connector, unplugging the connectors with as rapid a motion as possible to prevent arcing from damaging the connector. Opening both ends should stop the flow of current to the fault. Once the current ceases and is verified with a clampon ammeter, open all the fuse holders in the source circuit combiner box.

3. Test each fuse, one at a time, by removing it from the holder, performing the manufacturer's recommended continuity test, and then reinserting the good fuses into 
their respective open fuse holders (Do not close the fuse holder at this step-wait until step 19).

\section{A DANGER}

Do not close the fuse holder at this step-wait until step 19

4. Note the string from which the fuse was removed and set aside any blown fuses. Blown fuses are a common indicator of a faulted string.

5. Test the grounded conductor current on each string in the combiner. A blown fuse may also be predictive of current in the grounded conductor caused by a ground fault.

6. Test and record the $\mathrm{V}_{\text {oc }}$ of each string in the combiner box with the fuse holders open. The faulted circuit will have a lower $\mathrm{V}_{\text {oc }}$ than the other circuits unless the ground fault is on the grounded conductor home run.

a. NOTE: If the ground fault is on the grounded conductor, the fuse must be good for current to flow. If the fuse is blown and there is ground current, the $\mathrm{V}_{\mathrm{oc}}$ of the faulted string will be lower than that of the other source circuits. If the $\mathrm{V}_{\mathrm{oc}}$ is similar to the other strings, the fault may be intermittent.

7. Record the $\mathrm{V}_{\mathrm{oc}}$ of all the strings. Divide the voltage of one of the good strings by the number of modules in series to determine the module voltage (example: $\mathrm{V}_{\mathrm{oc}}=480 \mathrm{~V} ; 12$ modules in series; $\mathrm{V}_{\text {oc }}$ per module $\left.=480 \mathrm{~V} \div 12 \mathrm{mod}=40 \mathrm{~V} / \mathrm{mod}\right)$.

8. The modules in most PV source circuits are in series, so the ground fault location can be based on the voltage of the faulted string (example: $V_{\text {faulted }}=400 \mathrm{~V} ; 400 \mathrm{~V} / 40 \mathrm{~V} / \mathrm{mod}=$ 10 modules; fault location may be 10 modules back from the high voltage (output) side of the string).

9. Once the faulted circuit is identified, find its location in the array. Ideally, a circuit map will be available in the combiner box or on the as-built drawings. However, all too often the circuits must be manually traced. A circuit with current can be found with the use of a dc clamp-on ammeter to clamp around various array conductors.

10. Once the faulted string in the array is identified, find each end. Use insulated gloves and any necessary, appropriate tool to release the connector, then unplug the connector with as rapid a motion as possible to minimize damage to the connector (if this was not done as part of step 1 in this phase). This should stop the flow of current (if any) to the fault.

11. Verify that any current on the grounded conductor is gone.

12. Examine the faulted string, module by module, starting at the estimated fault location (based on the measured voltage at the combiner box in step 7) until the fault is located.

13. Remove and replace the damaged module and/or repair the damaged conductors.

14. Verify that the damaged string has no solid voltage reading by testing the voltage at the combiner box for that string. (Note: if the circuit does not have a ground fault, the voltage reading will wander - particularly when the voltmeter is first connected to the circuit.) 
15. Plug in the grounded conductor end of the string. Verify that no current is on the circuit and that the voltage on the string at the combiner box is consistent with all the other source circuit $\mathrm{V}_{\text {oc }}$ readings in the combiner.

16. Replace blown source circuit fuse if necessary (Do not close the fuse holder at this stepwait until step 19).

\section{$\triangle$ DANGER}

Do not close the fuse holder at this step-wait until step 19

17. Verify that the grounded feeder in the combiner box has no current.

18. Verify that none of the grounded feeders in the PV output circuit combiner have current on them.

19. Close all the fuse holders and de disconnects on the array side of the main dc disconnect at the inverter.

\subsubsection{Phase 4-Final Verification and Startup}

1. Verify that there is no solid voltage reading between the grounded conductor and the ground. (Note: if the circuit does not have a ground fault, the voltage reading will wander-particularly when the meter is first connected to the circuit.)

2. If the ground fault fuse is blown, place a replacement fuse back in the holder, and close the fuse holder. For circuit breaker systems, close the circuit breaker.

3. Verify that no current is flowing through the grounding conductor to the ground fault protector as measured with a dc clamp-on ammeter. A reading below 0.5 amps with a dc clamp-on ammeter is considered zero since these meters are not accurate at very low current levels. (Note: It is normal for less than $10 \mathrm{~mA}$ to flow without ground faults in a 500-kW PV array.)

4. Begin the startup procedures for the inverter according to the manufacturer's installation manual. This generally includes closing the ac breakers and disconnects before closing the dc disconnecting means.

5. Turn the system on and verify that there is no current on the equipment grounding conductor. (Note: it is normal for less than $10 \mathrm{~mA}$ to flow without ground faults in a 500kW PV array.) 


\section{Testing Photovoltaic Systems With No Known Ground Faults}

Electrical insulation testing is one of several ways to sense or predict the failure of conductors in a PV system. "Megger" testing, as insulation testing is often called, is a name brand of a product from a company that pioneered this particular type of testing. This product typically imposes a selectable voltage of 50-1500 Volts on conductors and equipment designed to operate at lowvoltage (1000 Volts or less). Conductor damage of any kind, whether caused by installation damage, thermal cycling of conductors and conduit, or overheating from poor connections may cause the conductor insulation to deteriorate. This damage can lead to small leakage current that is considerably greater than normal leakage from undamaged conductors. Insulation tests are often used during construction in system acceptance and commissioning procedures to detect damage during construction. These tests are not commonly used in maintenance and operation unless troubleshooting is required to find a ground fault. PV modules and 600-Volt rated wire should be capable of being tested at $1000 \mathrm{~V}$, because they must have passed certification tests at twice the rated voltage plus $1000 \mathrm{~V}(600-\mathrm{V}$ cable: conductor certification test is $600 \mathrm{~V} \times 2+$ $1000 \mathrm{~V}=2200 \mathrm{~V})$. Furthermore, the insulation testing is a short-term test and does not damage the wire or module insulation.

\subsection{Insulation Testing Procedure}

Before testing specific products and installations, including strings of modules, confirm that the testing (above rated voltage) will not void the warranties. Written permission should be obtained from the module manufacturer for testing procedures if they did not already provide approved insulation testing guidelines. Some manufacturers explicitly disallow insulation testing on their modules. Nevertheless, the most common locations of ground faults in PV systems are in the module wiring and modules.

Testing using the 500-V setting may be appropriate for some modules. When testing at a $500-\mathrm{V}$ setting, any surge protection devices (SPDs) must be removed from the circuit to keep from damaging the SPD. These SPDs may be wired directly to the fused bus of the combiner box, may be wired to a tilt-out fuse holder, or may be a plug-in device. Lower testing voltages are necessary if the SPDs are not removed. Insulation testers are now available with 50-V settings that will not damage the SPDs. The added benefit of a low-voltage insulation test is that it can detect problems with SPDs. Leaking SPDs are common in older PV systems.

Some expected resistance values are covered in the procedures; however, using a specific resistance threshold for insulation resistance testing often creates problems for field technicians. The key to insulation testing is to look for relative differences in resistance values rather than absolute values of resistance. Gathering data is simple with insulation resistance testing. Interpreting the data requires experience.

\subsection{Field Procedure}

Tools include:

- Insulation tester (with 50-V setting-e.g., Megger model MIT420, or MIT430 testers, or equivalent) 
- PPE rated for maximum system voltage (hand, head, etc.)

- Other PPE as necessary (eye, fall, etc.)

- Screwdriver or combiner box key if applicable

- De clamp-on ammeter

- Dc voltmeter

- Electrical tape

- System drawings - string wiring diagram, disconnect locations

- Recording device (pen and paper, laptop, or tablet).

\subsubsection{Phase 5: Testing the Whole Array at the Photovoltaic Output Circuit Combiner}

1. Perform Phase 1 testing.

2. Perform Phase $2 a$ or Phase $2 b$ testing depending on, respectively, whether or not current exists in the grounding circuit.

3. Record test conditions including ambient temperature and plane of array irradiance. (NOTE: temperature, irradiance, moisture, and wind can all affect resistance measurements.)

4. If testing at more than $50 \mathrm{~V}$, remove any surge protection devices from the circuits being tested.

\footnotetext{
$\widehat{\triangle}$ DANGER

If no disconnects are available to de-energize PV output circuit combiner fuses, consider removing fuses at night. If fuses are removed while energized, confirm that NO CURRENT is on the fuse holder before opening it. For large PV systems (up to $500-\mathrm{kW}$ per inverter), required electrical PPE based on available energy, including arc-fault suit is necessary to perform this fuse removal during daylight hours. This is due to the danger involved with removing energized fuses in a PV array.
}

4. Remove voltage from the PV output circuit combiner fuses, if it is equipped with fuses. Remove PV output circuit combiner fuses or open PV output circuit combiner circuit breakers as equipped.

5. Check for current on the grounded PV output circuit conductors using a clamp-on current meter.

6. At the PV output circuit combiner, remove the grounded conductors one at a time from the grounded conductor busbar. Ensure the uninsulated end of the conductor does not touch anything. It is good practice to install a twist-on wire splice (wire nut) or to cover the exposed end with electrical tape to prevent unintended contact, as this conductor can have several hundred volts on it when not grounded.

7. Set the insulation tester in a stable location. Attach the red lead to the red terminal on the tester. Attach the black lead to the black terminal on the tester. 
8. Set the meter to the lowest voltage setting - $50 \mathrm{~V}$ if available.

9. For each circuit, attach the black (negative) lead from the tester to the ground busbar in the PV output circuit combiner. Attach the red (positive) lead from the tester to the negative conductor of the circuit under test.

10. Press and hold the "Test" button for a specific and consistent time interval—at least 15 seconds and preferably 30-60 seconds. (NOTE: The product instruction manual for the tester may have a recommended time interval. Record the time interval used.)

11. Closely monitor the readings throughout the duration of each test and look for abnormal fluctuations. NOTE: At the beginning of each test, the insulation tester will generally display low resistance for a brief period as current flows into the circuit and voltage builds. The voltage and insulation resistance reading should build to a similar value for similar circuits when the circuits have no faults.

12. Record the result at the end of each timed interval. Insulation resistance measurements will vary based on system age, moisture, temperature, and the size of the circuit under test. Because absolute numbers vary based on these and other conditions, typically a PV output circuit conductor with a value greater than $100 \mathrm{k} \Omega$ is considered passing (reference readings taken during commissioning if available). Look for outliers. If one or more readings shows a resistance that is $1 / 10^{\text {th }}$ or less than "good" conductors, this may be an indication of a damaged conductor or module.

13. Repeat the test for each output circuit until all output circuits are tested.

a. If an output circuit fails the test, isolate the conductors from the source circuit combiner and test the insulation of the positive and negative source circuit home run conductors relative to the ground separately. Replace the faulted conductor and repeat steps 9-12.

b. If all source circuit home run conductors pass the test, the problem is in the source circuit combiner box associated with the PV output circuit registering low insulation resistance. Proceed to Phase 6.

\subsubsection{Phase 6: Testing Subarray at Individual Source Circuit Combiners}

Having completed the tests in Phase 5 proceed with the following steps.

1. Record test conditions, including ambient temperature and plane of array irradiance.

2. If testing at more than $50 \mathrm{~V}$, remove any surge protection devices from the circuits being tested.

3. After confirming that there is no current on each circuit, open all source circuit combiner fuses.

4. At the source circuit combiner, remove grounded conductors one at a time from the grounded conductor busbar. Ensure the uninsulated ends of the conductors do not touch anything conductive. It is good practice to install a twist-on wire splice (wire nut) or to cover the exposed end with electrical tape to prevent unintended contact when not actively testing the circuit. 
5. Set the insulation tester in a stable location. Attach the red lead to the red terminal on the tester. Attach the black lead to the black terminal on the tester.

6. Set the meter to lowest voltage setting - $50 \mathrm{~V}$ if available.

7. For each circuit, attach the black (negative) lead from the tester to the ground busbar in the PV source circuit combiner. Attach the red (positive) lead from the tester to the negative conductor of the circuit under test.

8. Press and hold the "Test" button for a specific and consistent time interval — at least 15 seconds (record the time interval used).

9. Closely monitor the readings throughout each test and look for fluctuations. NOTE: At the beginning of each test, the insulation tester will generally display low resistance for a brief period as current flows into the circuit and voltage builds. The voltage and insulation resistance reading should build to a similar value for similar circuits where the circuits have no faults.

10. Record the result at the end of each timed interval. Insulation resistance measurements will vary based on the system age, moisture, temperature, and the size of the source circuit under test. Because absolute numbers vary based on these and other conditions, typically a source circuit conductor, including PV modules, with a value greater than $1 \mathrm{M} \Omega$ is considered passing (reference readings taken during commissioning if available). Look for outliers. If one or more readings shows a resistance that is $1 / 10^{\text {th }}$ or less than "good" conductors, this may be an indication of a damaged conductor or module.

11. Repeat the test for each source circuit until all source circuits are tested.

c. If a source circuit fails the test, isolate the conductors from the PV modules and test the insulation of the positive and negative source circuit home run conductors relative to the ground separately. Replace the faulted conductor and repeat steps 7-10.

d. If all source circuit home run conductors pass the test, the problem is in the PV modules or PV module wiring associated with the source circuit. Return to step 5 of Phase 3 and complete the remaining Phase 3 tests. 


\section{Retrofitting Existing Photovoltaic Systems With High-Resolution Ground Fault Detectors}

This section provides guidance on recommended approaches for installing high-resolution ground current detectors that can be retrofitted to existing PV systems by qualified field personnel. This approach involves the permanent installation of high-resolution ground current detectors. These detectors are more sensitive than typical detection equipment required in a grounded PV system. Products are now available that accurately measure ground currents less than $10 \mathrm{~mA}$. Previously, a PV system using an 800-kW inverter was required only to detect ground current above $5000 \mathrm{~mA}$. However, current above $100 \mathrm{~mA}$ may indicate faulty conductor insulation on most $800-\mathrm{kW}$ PV arrays. The $100 \mathrm{~mA}$ value is $1 / 50^{\text {th }}$ of the previously required detection value for the inverter ground fault fuse or circuit breaker. In an $800-\mathrm{kW}$ PV array, potentially dangerous faults will go undetected if the current does not exceed $5000 \mathrm{~mA}$. The solution for more sensitive fault level detection is to install a high-resolution residual current monitor (RCM), also called a residual current detector. By installing permanent high-resolution RCMs, faulty insulation can then be detected as it occurs, allowing the damage to be repaired long before it becomes a fire hazard.

The baseline ground current of the system needs to be determined when the system is known to be functioning normally, ideally as part of the commissioning process. This information can be used to establish the appropriate RCM trigger setting. Data from Solar America Board for Codes and Standards research projects shows that a "normal" ground current value is unique to each system and depends on a variety of factors, including the inverter and the climate [4]. Solar America Board for Codes and Standards research also shows that sufficiently long data averaging can be employed to identify and differentiate storm-related transient currents from persistent ground fault currents [4].

The setting of an RCM requires an understanding of the above conditions. Most plant owners and operators are concerned about system operation and availability. One option is to respond to a current trigger by tripping an alarm rather than by shutting down the PV system. By using an alarm, a low threshold can be chosen for the RCM ground fault detection without incurring lost production from false alarms. This provides maximum protection against potential ground faults. When the alarm is triggered, the output of the RCM can be monitored to see if the reading was a legitimate fault, a transient fault, or a possible false alarm. Upon reviewing RCM triggers, and accounting for variables such as baseline ground current and storm-related transients, revised alarm threshold parameters can be established to prevent false alarms.

\subsection{Installing a Residual Current Monitor on a Photovoltaic Array With a Large Inverter}

This section describes the process to install and set an RCM at a large PV inverter. The product that will be discussed is made by Bender Corporation. Other products by other manufacturers may have similar specifications, accuracy, and field experience. 
The RCM discussed in this section uses solid-core, rather than split core, current transducers; thus, the inverter input circuit conductors must be removed from the inverter input so the corresponding pairs of circuit conductors can be run through the transducers. This may be most easily accomplished in the PV output circuit combiner. The largest transducer that Bender makes is $21 \mathrm{~cm}(8-1 / 4 \mathrm{in}$.) inner diameter. This is large enough for the output conductors of most PV output circuit combiners for $800-\mathrm{kW}$ units. The output of a PV output circuit combiner might have six pairs of $750-\mathrm{kcmil}$, which would be less than $40 \%$ conduit fill in a 6 -in. conduit. It would then be possible to run all conductors from that $800-\mathrm{kW}$ unit through one of these $8-1 / 4$ in. transducers. Figure 4 is a photo of an installed monitor, and Figure 5 shows a diagram of another method in which a single residual current detector could be installed on the output of a PV output circuit combiner.

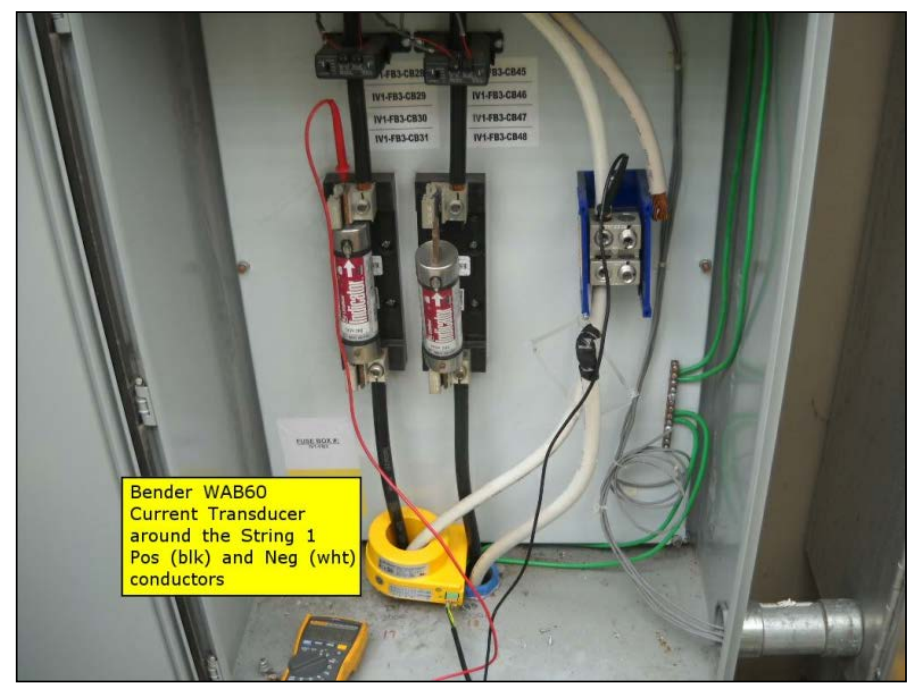

Figure 4. Test setup showing a single monitor

If higher resolution measurements are desired, breaking the array into sets of one to three source circuit combiner feeders can be an attractive solution. Figure 6 shows where a transducer is placed around each source circuit combiner feeder circuit entering a PV output circuit combiner. A 800-kW PV system with 200-amp fuses installed in the PV output circuit combiner will have about 10-12 source circuit combiner circuits. The Bender RCMA460 can measure up to 12 individual current transducer channels and provides a single alarm circuit. The array can be divided into 2, 3, 4, 6, or even 12 separate circuits. One advantage to this method is that the alarm threshold can be reduced to extremely low levels (less than $50 \mathrm{~mA}$ for most PV arrays) without concern about false alarms. Another advantage with multiple transducers is that they drastically reduce troubleshooting time by narrowing down fault location. This is especially helpful with intermittent faults, as data are time stamped and can be compared with other operating conditions such as weather. The Bender RCMA490 can provide 12 alarm circuits if it is deemed necessary to alarm or control separate circuits. One application of this alarm system would be to automatically open individual contactors associated with specific PV output circuits. By alarming an individual circuit and opening its contactor, a section of the PV array could be automatically isolated from the rest of the system if a fault were to occur. 


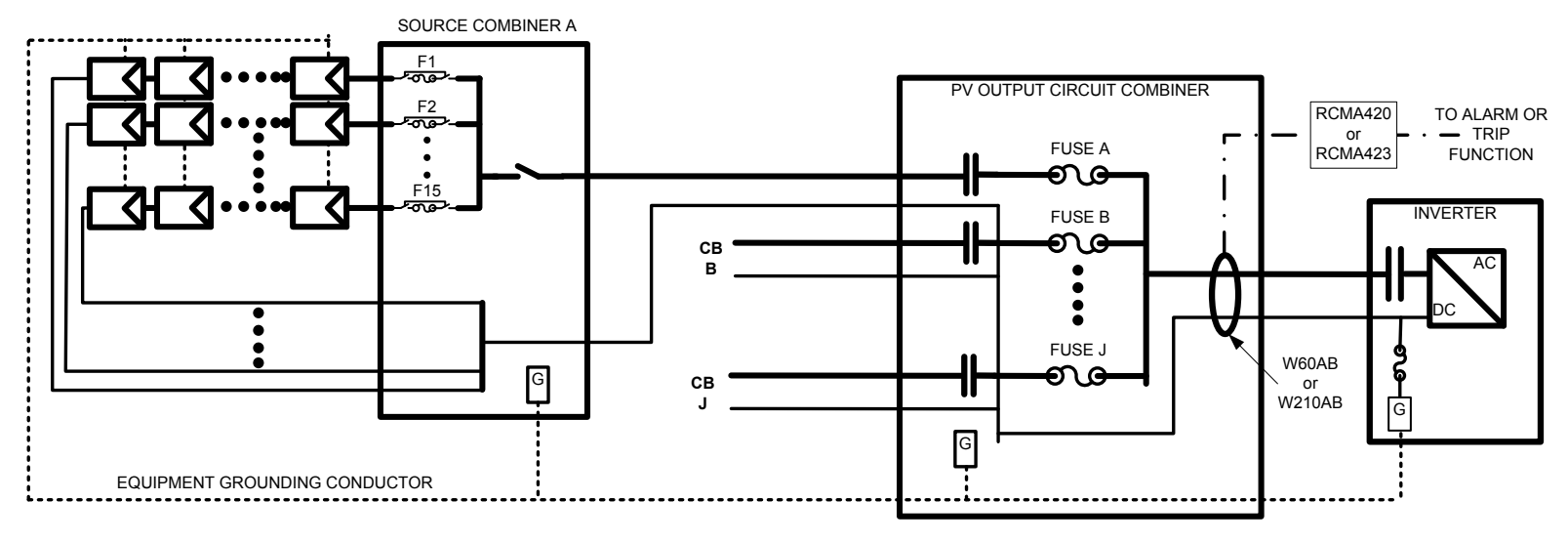

Figure 5. Single monitor setup

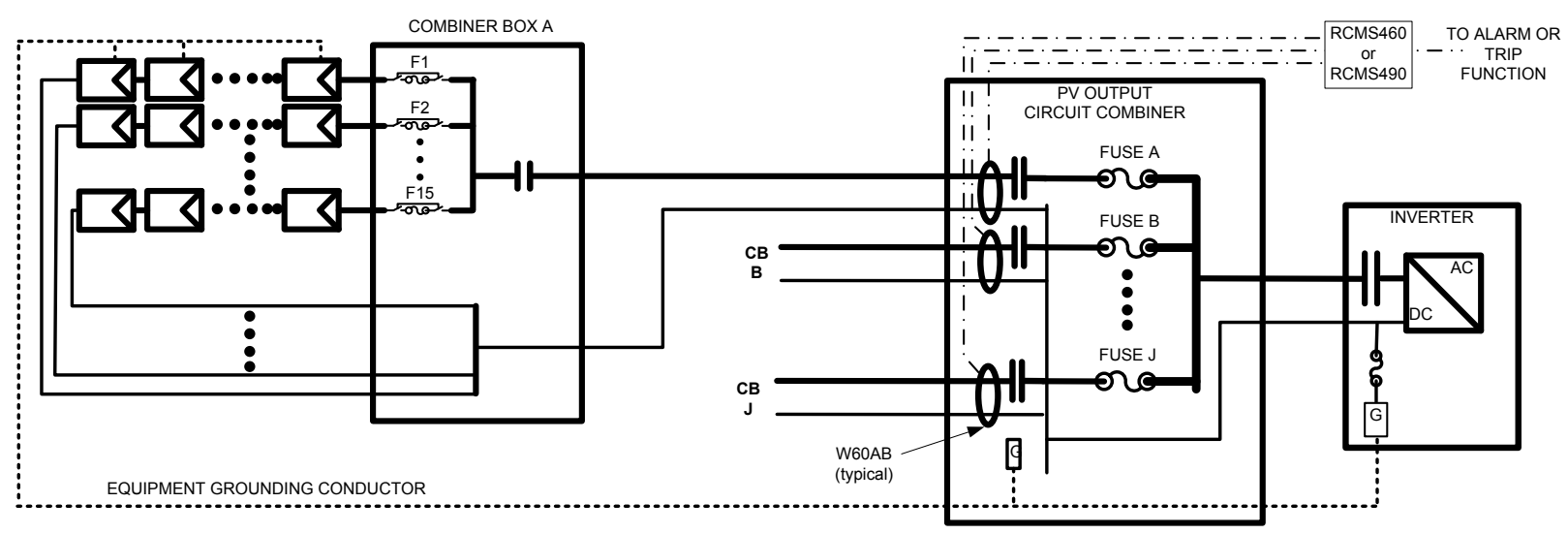

Figure 6. Multiple monitor setup

It is recommended that grounded PV systems have ground fault detection circuits capable of accurately measuring $100 \mathrm{~mA}$ of residual current and be set to detect no higher than $300 \mathrm{~mA}$ of residual current. By detecting residual currents in this low range, alarms can be monitored and service personnel dispatched in a timely manner long before a leakage current causes a catastrophic failure. Normal residual currents for $800-\mathrm{kW}$ PV systems are less than $30 \mathrm{~mA}$ for most flat-plate PV systems that have been measured to date [4]. By incorporating moving averages into the measurements, current spikes caused by lightning or inverters turning on and off can be effectively smoothed so the monitor alarms only the higher residual current that is abnormal and indicative of faults.

\subsubsection{Selecting and Installing the Appropriate Residual Current Monitor}

The following is a set of decision steps for selecting and installing a Bender residual current monitor for PV systems up to $800 \mathrm{~kW}$ per inverter. Decision steps for other manufacturer's equipment would follow steps similar to the following. 
1. Decide whether a single measurement is sufficient or if multiple measurements are preferred.

a. Single-RCMA420 for up to $100 \mathrm{~kW}$; RCMA423 for up to $800 \mathrm{~kW}$

b. Multiple-RCMA460 for up to 12 inputs and one alarm; RCMA490 for up to 12 inputs and 12 alarms

2. Select the current transducers necessary for method selected in step 1 .

a. Single-W60AB for up to $100 \mathrm{~kW}$ (with RCMA420); W210AB for over $100 \mathrm{~kW}$ up to $500 \mathrm{~kW}$ (with RCMA423)

b. Multiple-W60AB per circuit up to $100 \mathrm{~kW}$ - need an AN420 power supply for every six transducers (with either RCMA460 with one alarm or RCMA490 for up to 12 alarms)

3. Choose what the alarms will interface with in the PV system.

a. Alarm interface with real-time data system output to provide remote notification of a fault.

b. Shut down whole system-use the emergency stop or similar function in the inverter while providing remote notification of a fault.

c. Shut down individual circuits - operate shunt-trip breakers or contactors in the combiner boxes related to faulted circuits to interrupt only faulted circuits (this requires opening both the positive and negative conductors so the circuit is fully isolated from the remainder of the system). Provide remote notification of a fault (requires RCMA490).

4. Install equipment - it is important that wherever the transducers are installed the equipment certifications are properly maintained. Sensing circuits connected to the current transducers must be rated according to the highest voltage to which cables are exposed (usually $600 \mathrm{~V}$ or higher). Factory-installed conductors in certified electrical hardware will have their certification voided if conductors are disconnected and reconnected without a field certification. Therefore, it is best to install current transducers on field installed conductors so that factory certifications are not voided. All gridconnected inverters built after 2005 have built-in ground fault detectors that met the requirements of 2005 through 2011 NEC.

NOTE: The 2014 NEC has revised the language of section 690.5 requirements updating the 2011 edition. The 2014 NEC version of 690.5 requires that ground fault devices detect and interrupt ground faults on all conductors, including intentionally grounded conductors. An alarm circuit alone would not be sufficient to meet the 2014 NEC. The ground fault device would have to interface with something that interrupts the ground fault to meet the 2014 NEC. This interruption could be as simple as opening the connection to ground and shutting off the inverter, or it could be more elaborate and isolate the circuit with the ground fault while allowing the inverter to continue to operate. 


\subsubsection{Additional Installation Notes}

Figure 7 shows the installation of Bender current transducers in a PV output circuit combiner with $600-\mathrm{V}$ rated conductors. The accompanying monitor is located in an external box on the inverter (Figure 8) so that the display can be viewed without shutting down the inverter or exposing the technician to energized conductors or busbars in the PV output circuit combiner. Figure 9 shows a new PV output circuit combiner product with the Bender components factory installed.

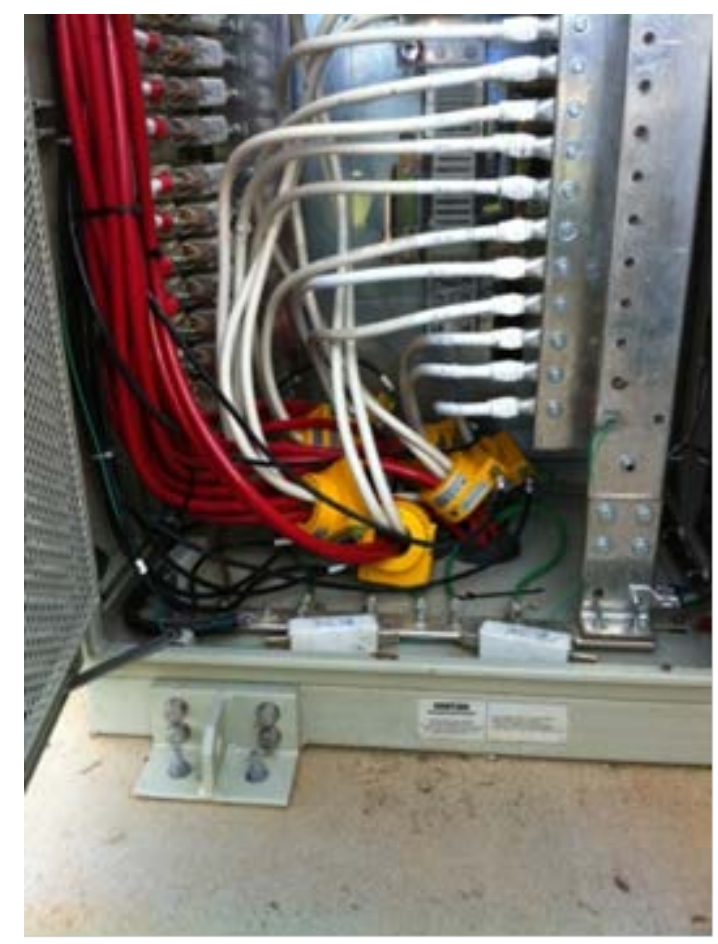

Figure 7. Multiple current transducers in PV output circuit combiner

Note about residual current monitors:

This note is to clarify that the author is aware of the following non-detection issue for some specific PV systems and that it does not generally apply to the systems discussed in this document. Recent news among those working in the international PV standards arena is discovery of a non-detection zone for products like the Bender residual current monitor. The issue relates to the fact that these devices do not measure currents that have a frequency above 2 $\mathrm{kHz}$. This phenomenon was discovered in Europe on a system that was very different from the PV systems addressed in this document. In general, PV systems that use a fuse as a ground detector have a very low impedance path to ground at the inverter, making the problem observed in Europe extremely unlikely for PV systems with a fuse as a ground detector. 


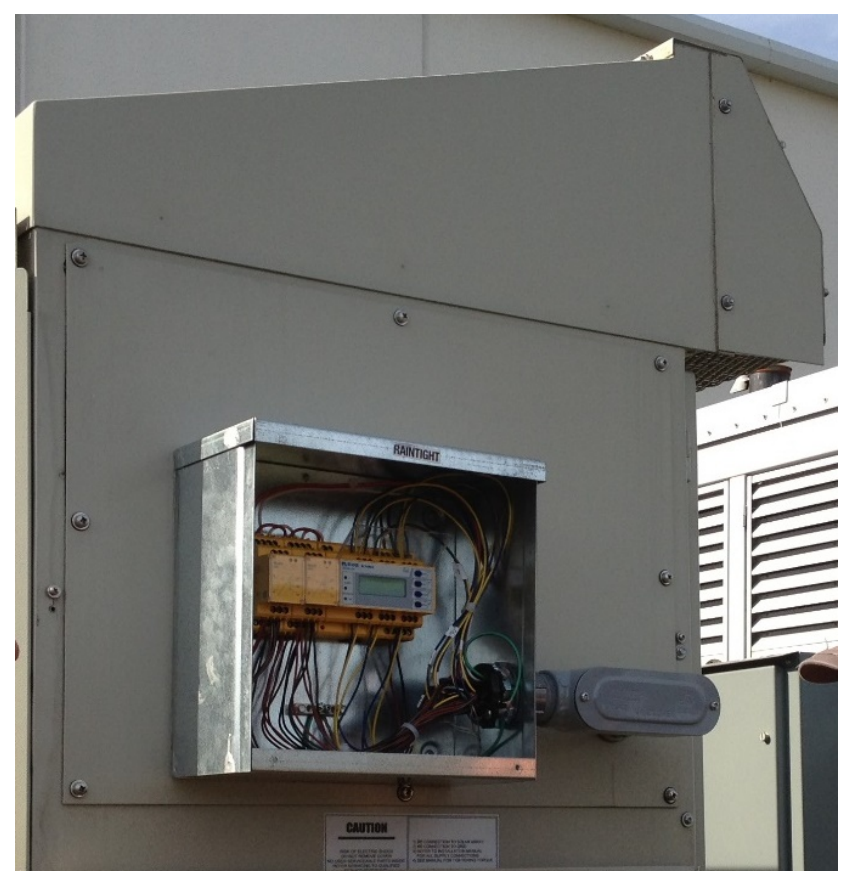

Figure 8. Monitor in external enclosure

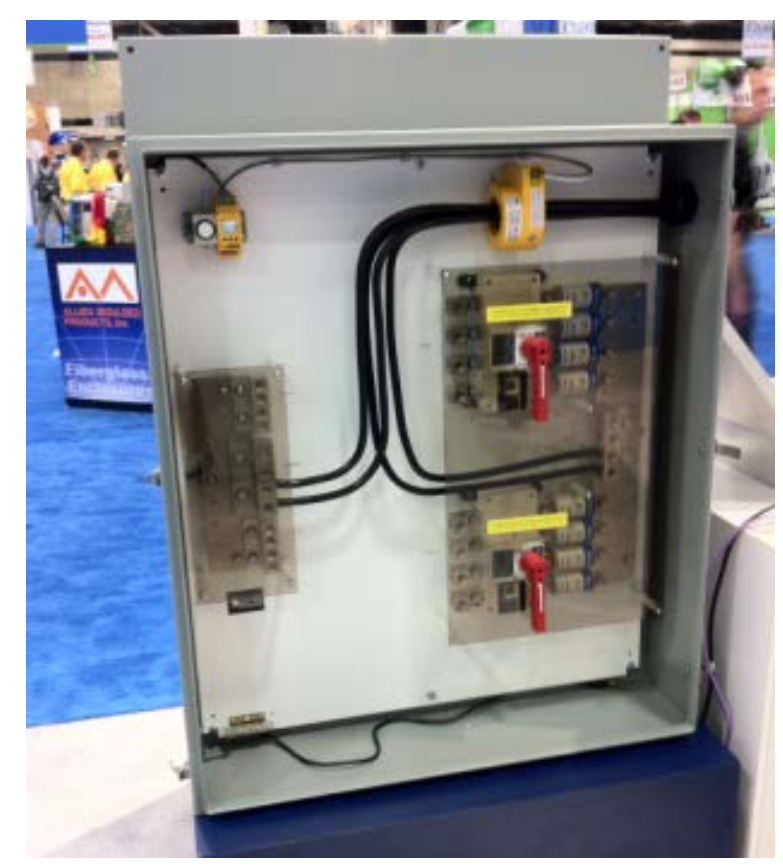

Figure 9. PV output circuit combiner equipped with residual current monitor 


\section{Finding Arc-Fault Failure Locations in a PV Array}

Recently, many questions on field testing have been related to finding the location of arc faults after an arc-fault detector has activated. This is particularly difficult when the circuit is still intact. Few field technicians would have problems finding an arc-fault location in a three-string array where one of the three strings is open circuit. The open-circuit string is the likely fault location, and the technician can pick their favorite method to find which connection is bad. Some might use "divide and conquer," where the voltage between the middle of the string to each of the two ends is tested to see which has voltage. Obviously, the end without voltage is the faulted section and the "divide and conquer" method can be continued (depending on how difficult it is to unplug modules).

Open circuits with arc faults are relatively easy to find, but what about when the circuit is still intact? The circuits may have good open circuit voltage, and even decent current, so what can be done with a case that may be intermittent? This has been the reason for many questions. In this case, the next tool to employ is an IR camera. Arc faults are the result of bad connections. Connections may have satisfactorily checked out at installation, or at the last O\&M check, but possibly something may have happened since then. If an arc fault has truly occurred, there could be an intermittent connection that is getting worse. It could be a wire coming loose in a combiner box terminal, a connector coming loose that was not fully latched, an improperly crimped plug connector, or a connection coming loose in the module itself. In all of these cases, there will often be significant heat being generated at the connection. Combiner box problems or module defects are easy to find with an IR camera. The challenge comes when the connector is the location of the intermittent arc fault. Many rooftop systems do not have good access to the connectors, so getting a clean IR image of a connector can be difficult to view. Unfortunately, connectors are a common source of arc-fault fires, so they must be checked. Even without an IR camera, connectors, modules, and combiner boxes can be visually checked for melting or heat damage. Overheating in modules often causes browning of the encapsulants or backsheets. Overheating in combiner boxes may cause discoloration or deformation of insulating plastics. Overheating on connectors often causes distortion of the connector plastic.

Finding arc faults is currently more of an art rather than common practice. Over the next few years it is envisioned new products will be developed to establish the location of arc faults. For example, there could be some type of signal generator used with a receiver identifying where the signal is attenuated, thus identifying that location as a bad connection. These types of troubleshooting devices are used throughout the electrical industry for different purposes and could probably be repurposed for this application. In the future, this type of concept could benefit troubleshooting PV arrays that have triggered an arc-fault detector. 


\section{Retrofitting Existing Photovoltaic Systems With Arc Fault Detectors}

Another relevant known fire hazard that must be addressed for PV systems is series arc faults. Several PV system arc fault fires have occurred throughout the United States in the past several years, but very few have been widely publicized. Efforts are underway to have information released on these fires; however, this document focuses on how to mitigate the hazard rather than providing information on previous arc fault fire events.

The most common type of arc faults are series arc faults caused by bad connections, or "failure of intended continuity"- as quoted from the 2011 NEC. Article 690.11 in the 2011 NEC requires arc fault detection on all PV systems operating above 80 volts and mounted on buildings. The 2014 NEC extends that requirement by removing the limitation of PV systems mounted on buildings so that ground-mounted systems must also have arc fault detection.

A series arc fault refers to the situation where current continues to circulate even when an intentional connection becomes disconnected. This can occur when a module connector or a wire connected to a terminal in a combiner box becomes loose, or a solder joint separates in a module. If the circuit is carrying current when the connection begins to open, an arc can occur and remain for seconds, minutes, or even longer.

The biggest issue with mitigating arc faults today is that few products are available. As of early fall 2015, the only certified products available for the PV market containing arc fault detection were string inverters, battery charge controllers, and a few source circuit and output circuit combiner boxes. This means that few certified products exist for larger $800-\mathrm{kW}$ inverter PV systems making it extremely challenging to build a PV system with an $800-\mathrm{kW}$ inverter that is compliant with the 2014 NEC. Products that are designed for source circuit combiners, may not address PV output circuits, and have yet to see widespread use.

\subsection{Cost-Effective Ways To Implement Arc Fault Detectors on Larger Inverters}

Manufacturers of arc fault detectors are developing cost-effective products to address arc faults. The most cost-effective PV system designs should consider the overall installed cost, and be based on available, certified, reliable products. An important basic issue with arc fault detection is their signal-to-noise ratio. Detecting a one amp arc on a string may be challenging when the inverter is processing more than $1000 \mathrm{~A}$ of dc current. Ideally, inverter-level products will be developed that can detect arcs at this level. However, in the near term, products may be available sooner that operate at the string or source circuit inverter or combiner box level since the required current resolution is more manageable at source circuit currents. Current product literature should be consulted for up to date specifications.

Source circuit-level devices can provide very high resolution and pinpoint the location of a fault in a PV array; however, these may be too costly to implement on a $1000-\mathrm{kW}$ PV array feeding an $800-\mathrm{kW}$ inverter. Combiner box devices are likely to be the first cost-effective products for central inverter PV system designs. These low-current devices are being implemented at the source circuit combiner box level rather than at the PV output circuit combiner box. 
Given the low likelihood of arc faults, it may be acceptable to use either the inverter shutdown or the source circuit combiner shutdown method with little difference in system availability. However, if nuisance tripping by the arc fault detector is a concern, one method to reduce its impact is for the arc fault detector to trip only the circuit in which the arc was detected. Figures 10 and 11 show two methods for implementing an arc fault detection system. As certified products become available, the options and costs can be refined to develop the best design to meet the NEC requirement. The three methods shown in Figures 10, 11, and 12 are similar to the RCM options discussed earlier. In fact, the location for arc fault devices is similar, if not the same as for RCMs. In the future, devices may be developed that perform both functions. Because the NEC requires that the arc fault detector interrupt the arcing current, the arc-fault device must be incorporated into a method that stops the flow of current on the arcing circuit. Methods to stop the flow of current may be the inverter emergency stop function, contactor or shut-trip disconnecting devices.

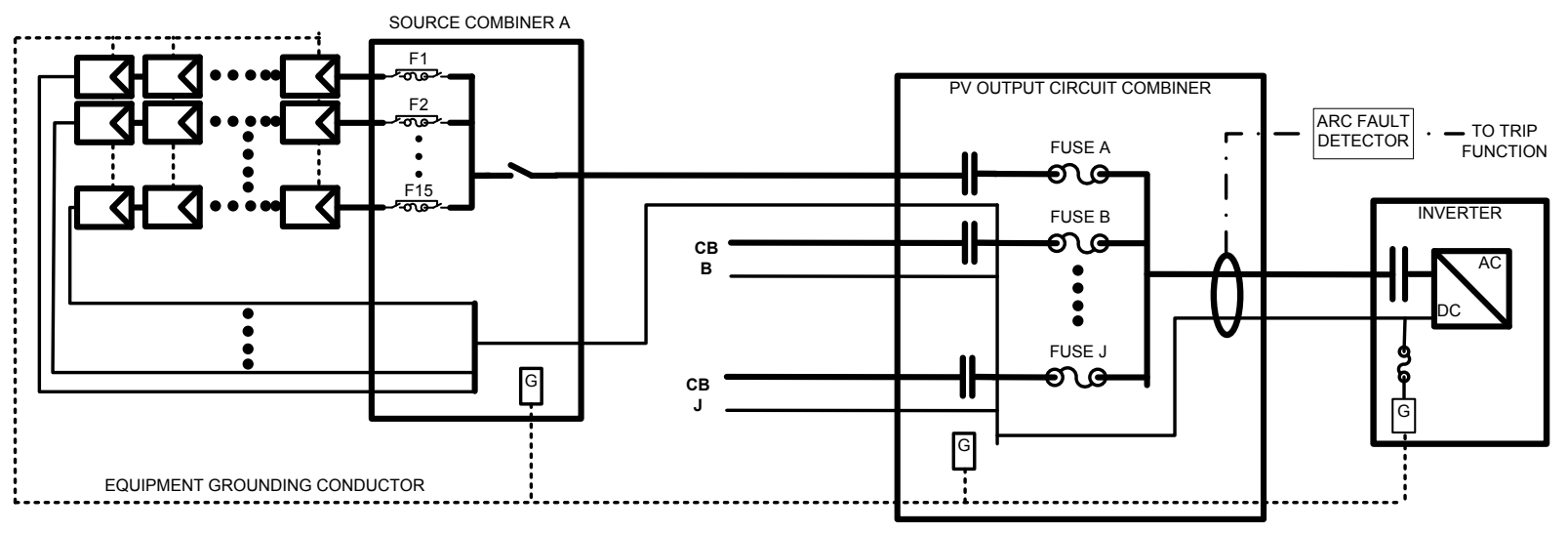

Figure 10. Single arc fault detector for the whole system

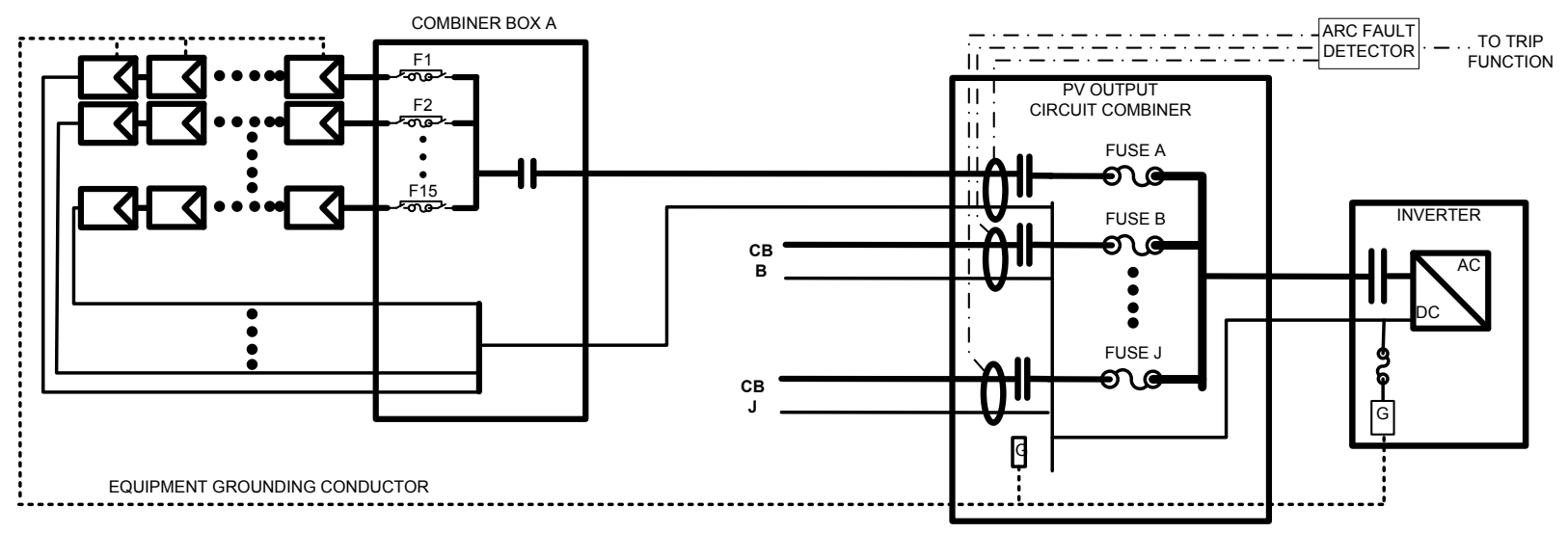

Figure 11. Multiple arc fault detector system 


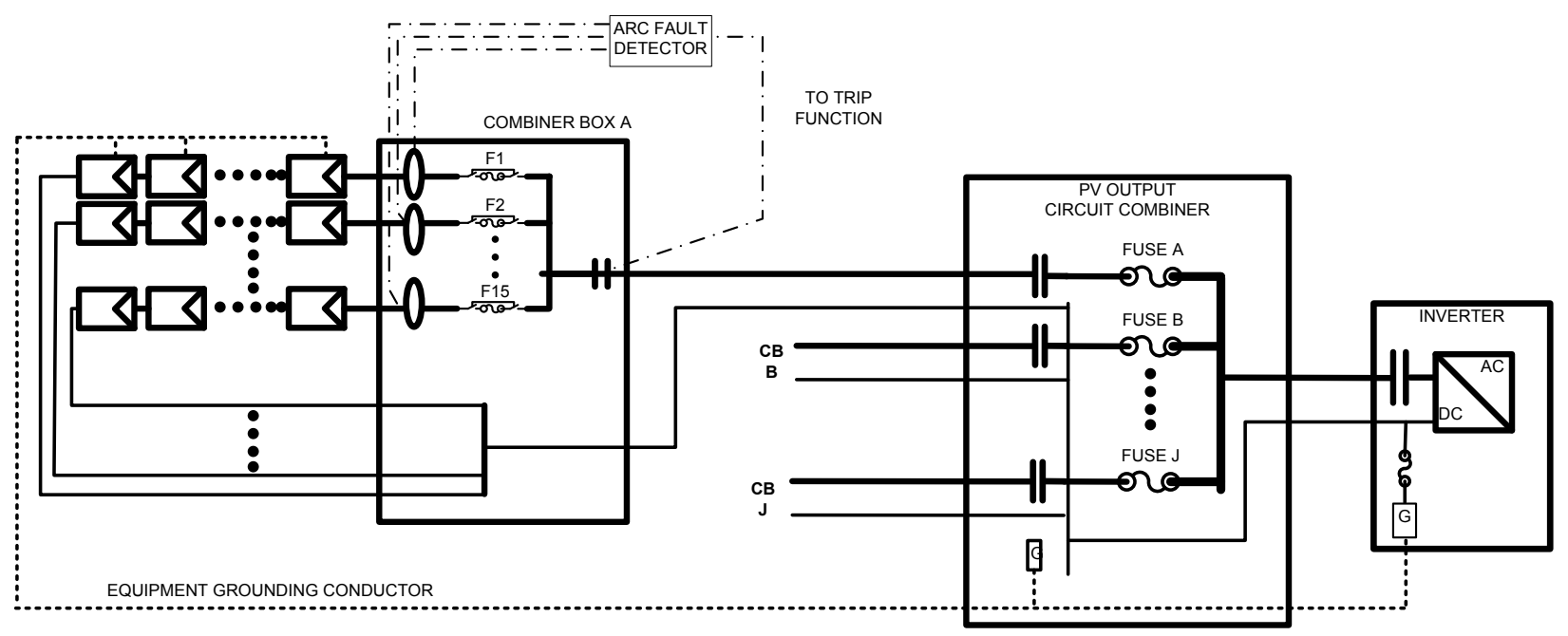

Figure 12. Source circuit arc fault detector system 


\section{New Requirements and Terminology in the 2017 NEC}

The ground fault blind spot results from the way, until recently, most PV systems installed in the U.S. are grounded for safety. These system safety methods are generally different from the way safety is approached in other countries. The ground fault detection resolution methods can be improved in current systems to achieve similar levels as is implemented in non-U.S. PV system designs. Some inverter manufacturers selling to the U.S. market already offer upgrade options to factory install higher resolution ground fault detection systems.

The 2017 National Electrical Code will have several clarifications related to how PV systems should be configured for safe operation. The 2017 NEC will acknowledge the fact that most PV systems currently being installed, and having been installed for over a decade, are not solidly grounded. Actually, most PV systems in the U.S. only use ground as a reference for their groundfault detectors. As this document has discussed, these early style ground-fault detectors have been shown to be insufficient for safety. Since our systems are not solidly grounded, it does not make sense for these systems to follow the same rules as grounded systems.

In fact, following rules for solidly grounded systems has resulted in some very unsafe practices. For instance, most PV systems installed between 2001 and 2014 used the fuse method for ground-fault detection. If a fault occurs on the ungrounded conductor, the fuse clears and the previously grounded side of the system is raised to the opposite voltage. In other words, a +500 Volt system when faulted will push the negative conductor to -500 Volts. The very real safety hazard is that all the negative connections in the system are typically bolted connections with no disconnects to isolate those connections. In order to fix the system, the technician must work on hot conductors or wait until nighttime. By identifying that PV systems are not solidly grounded, it follows that a disconnecting means must open both positive and negative conductors. This results in a safe working environment since the technician now has a disconnecting means to safely isolate a faulted array from an inverter or other electrical equipment. 


\section{Closing Remarks}

The ground fault blind spot results from the way, until recently, most PV systems installed in the U.S. are grounded for safety. These grounding methods for system safety are generally different than safety designs in other countries. The ground fault detection resolution methods can be improved in current systems to achieve similar levels as is implemented in non-U.S. PV system designs. Some inverter manufacturers selling to the U.S. market already offer upgrade options to factory-install higher resolution ground fault detection systems.

Inverters used outside the United States generally operate non-isolated from the utility grid, with the dc PV array referenced to Earth through the utility ac connection, or isolated from the ground. In isolated ungrounded PV arrays, an isolation monitor operates continuously on the PV array, detecting and alarming failures of electrical insulation. These alternative system designs may have superior ground fault detection systems and are beginning to be accepted in the U.S. design and construction community. As the electrical codes and standards that govern PV systems more explicitly accept these designs, the combination of these "new" designs and upgrades to existing ground fault detector designs will effectively eliminate the ground fault blind spot.

Arc fault detectors are standard in most inverters under $50 \mathrm{~kW}$ and are available for source circuit combiners. System designers need to adjust their future designs based on NEC requirements enforced where their installations exist. As these products mature over the next few years, additional retrofit products will emerge that can cost-effectively address the ongoing concern about fires potentially started by series arc faults in existing PV arrays. 


\section{References}

1. B. Brooks. (2012). The Ground-Fault Protection Blind Spot: Safety Concern for Larger PV Systems in the U.S. Solar America Board for Codes and Standards. http://www.solarabcs.org/about/publications/reports/blindspot/pdfs/BlindSpot.pdf.

2. J. Flicker, J. Johnson. (2013). Photovoltaic Ground Fault and Blind Spot Electrical Simulations. Sandia National Laboratories Technical Report. http://energy.sandia.gov/wp/wp-content/gallery/uploads/SAND2013-3459-PhotovoltaicGround-Fault-and-Blind-Spot-Electrical-Simulations.pdf.

3. J. Flicker, J. Johnson. (2013). Analysis of Fuses for "Blind Spot" Ground Fault Detection in Photovoltaic Power Systems. Solar America Board for Codes and Standards. http://www.solarabcs.org/about/publications/reports/blindspot/pdfs/analysis_of fusesJune-2013.pdf.

4. G. Ball, B. Brooks, J. Johnson, J. Flicker, A. Rosenthal, J. Wiles, L. Sherwood, M. Albers, T. Zgonena (2013). Inverter Ground-Fault Detection "Blind Spot" and Mitigation Methods. Solar America Board for Codes and Standards. http://www.solarabcs.org/about/publications/reports/blindspot/pdfs/inverter_groundfault2013.pdf.

5. NFPA70, National Electrical Code 2011 edition, National Fire Protection Association, Quincy, MA, 2011.

6. UL1741, Inverters, Converters, Controllers and Interconnection System Equipment for Use With Distributed Energy Resources. Underwriters Laboratories. Northbrook, IL. 2010.

7. UL1699B, Photovoltaic (PV) Dc Arc-Fault Circuit Protection, Underwriters Laboratories. Northbrook, IL. 2011. 


\section{Appendix: Cost Analysis}

The following are scenarios for PV systems of various sizes from 500-100 kWac. These scenarios illustrate example costs for installing RCMs for larger PV systems. Costs include the monitors, current transducers, and installation labor. In some cases, computer interface hardware may be necessary to connect to various data systems. The Bender monitors offer an analogue 420-mA output that can be input directly into a data acquisition system that can translate that signal.

\begin{tabular}{|c|c|c|c|c|c|}
\hline \multicolumn{6}{|c|}{ Scenario \#1--500kWac/600kWdc PV System with 1 Transducer } \\
\hline \multicolumn{6}{|c|}{ Minimum Requirements } \\
\hline Item & Description & Qty & Cost/ltem & Co & \\
\hline Bender RCMA423-D-2 & Residual Current Monitor & 1 & 527.00 & $\$$ & 527.00 \\
\hline Bender W210AB & Current Transducer & 1 & $\$ \quad 675.00$ & $\$$ & 675.00 \\
\hline & & & & $\$$ & - \\
\hline & & & & $\$$ & - \\
\hline & & & & $\$$ & - \\
\hline Total Equipment Cost & & & & $\$$ & $1,202.00$ \\
\hline Labor and Materials: & & & & $\$$ & - \\
\hline Equipment x 1.0 & & & & $\$$ & $1,202.00$ \\
\hline (range from 0.5 to 1.5 ) & & & & $\$$ & - \\
\hline Total Cost & & & & $\$$ & $2,404.00$ \\
\hline Total Cost/Wdc & & & & $\$$ & 0.004 \\
\hline
\end{tabular}

\begin{tabular}{|c|c|c|c|c|c|}
\hline \multicolumn{6}{|c|}{ Scenario \#1a--500kWac/600kWdc PV System with 1 Transducer } \\
\hline \multicolumn{6}{|c|}{ Maximum Requirements } \\
\hline Item & & Qty & Cost/Item & Co & \\
\hline Bender RCMA423-D-2 & Residual Current Monitor & 1 & 527.00 & $\$$ & 527.00 \\
\hline Bender W210AB & Current Transducer & 1 & 675.00 & $\$$ & 675.00 \\
\hline \multirow[t]{3}{*}{ Data System Interface } & Communication Device & 1 & $\$ 1,600$ & $\$$ & $1,600.00$ \\
\hline & & & & $\$$ & - \\
\hline & & & & $\$$ & - \\
\hline Total Equipment Cost & & & & $\$$ & $2,802.00$ \\
\hline Labor and Materials: & & & & $\$$ & - \\
\hline Equipment x 1.5 & & & & $\$$ & $4,203.00$ \\
\hline (range from 0.5 to 1.5 ) & & & & $\$$ & - \\
\hline Total Cost & & & & $\$$ & $7,005.00$ \\
\hline Total Cost/Wdc & & & & $\$$ & 0.012 \\
\hline
\end{tabular}




\begin{tabular}{|c|c|c|c|c|c|}
\hline \multicolumn{6}{|c|}{ Scenario \#2--500kWac/600kWdc PV System with 3 Transducers } \\
\hline \multicolumn{6}{|c|}{ Minimum Requirements } \\
\hline Item & & Qty & Cost/Item & Cos & \\
\hline Bender RCMA460-D-2 & Residual Current Monitor & & $\$ 1,324.00$ & $\$$ & $1,324.00$ \\
\hline Bender W120AB & Current Transducer & 3 & 555.00 & $\$$ & $1,665.00$ \\
\hline \multirow[t]{3}{*}{ Bender AN420-2 } & CT Power Supply & 1 & $\$ \quad 215.00$ & $\$$ & 215.00 \\
\hline & & & & $\$$ & - \\
\hline & & & & $\$$ & - \\
\hline Total Equipment Cost & & & & $\$$ & $3,204.00$ \\
\hline Labor and Materials: & & & & $\$$ & \\
\hline Equipment x 1.0 & & & & $\$$ & $3,204.00$ \\
\hline (range from 0.5 to 1.5 ) & & & & $\$$ & - \\
\hline Total Cost & & & & $\$$ & $6,408.00$ \\
\hline Total Cost/Wdc & & & & $\$$ & 0.011 \\
\hline \multicolumn{6}{|c|}{ Scenario \#2a--500kWac/600kWdc PV System with 3 Transducers } \\
\hline \multicolumn{6}{|c|}{ Maximum Requirements } \\
\hline Item & & Qty & Cost/Item & Cos & \\
\hline Bender RCMA460-D-2 & Residual Current Monitor & & $\$ 1,324.00$ & $\$$ & $1,324.00$ \\
\hline Bender W120AB & Current Transducer & 3 & 555.00 & $\$$ & $1,665.00$ \\
\hline Bender AN420-2 & CT Power Supply & 1 & 215.00 & $\$$ & 215.00 \\
\hline \multirow[t]{2}{*}{ Data System Interface } & Communication Device & 1 & $\$ 1,600$ & $\$$ & $1,600.00$ \\
\hline & & & & $\$$ & - \\
\hline Total Equipment Cost & & & & $\$$ & $4,804.00$ \\
\hline Labor and Materials: & & & & $\$$ & - \\
\hline Equipment x 1.5 & & & & $\$$ & $7,206.00$ \\
\hline (range from 0.5 to 1.5$)$ & & & & $\$$ & - \\
\hline Total Cost & & & & $\$$ & $12,010.00$ \\
\hline Total Cost/Wdc & & & & $\$$ & 0.020 \\
\hline
\end{tabular}

The cost per dc Watt is computed to help owners understand the relative cost of the upgrade relative to the system size. For scenario 1 with the $500-\mathrm{kW}$ inverter, the lowest cost solution is a single current transducer with a single monitor. If no data system interface equipment is necessary, the total cost of the installation may be as low as $\$ 2,500$, which equates to $\$ 0.004 / \mathrm{kW}$. This configuration may not be possible if all the conductors cannot be routed through a single $210-\mathrm{mm}$ diameter transducer. To bound costs on the upper end, scenario 3 for the $500-\mathrm{kW}$ inverter system includes six current transducers, data system interface hardware, and installation costs on the high end. This results in a higher end cost of $\$ 0.022 / \mathrm{W}$. 


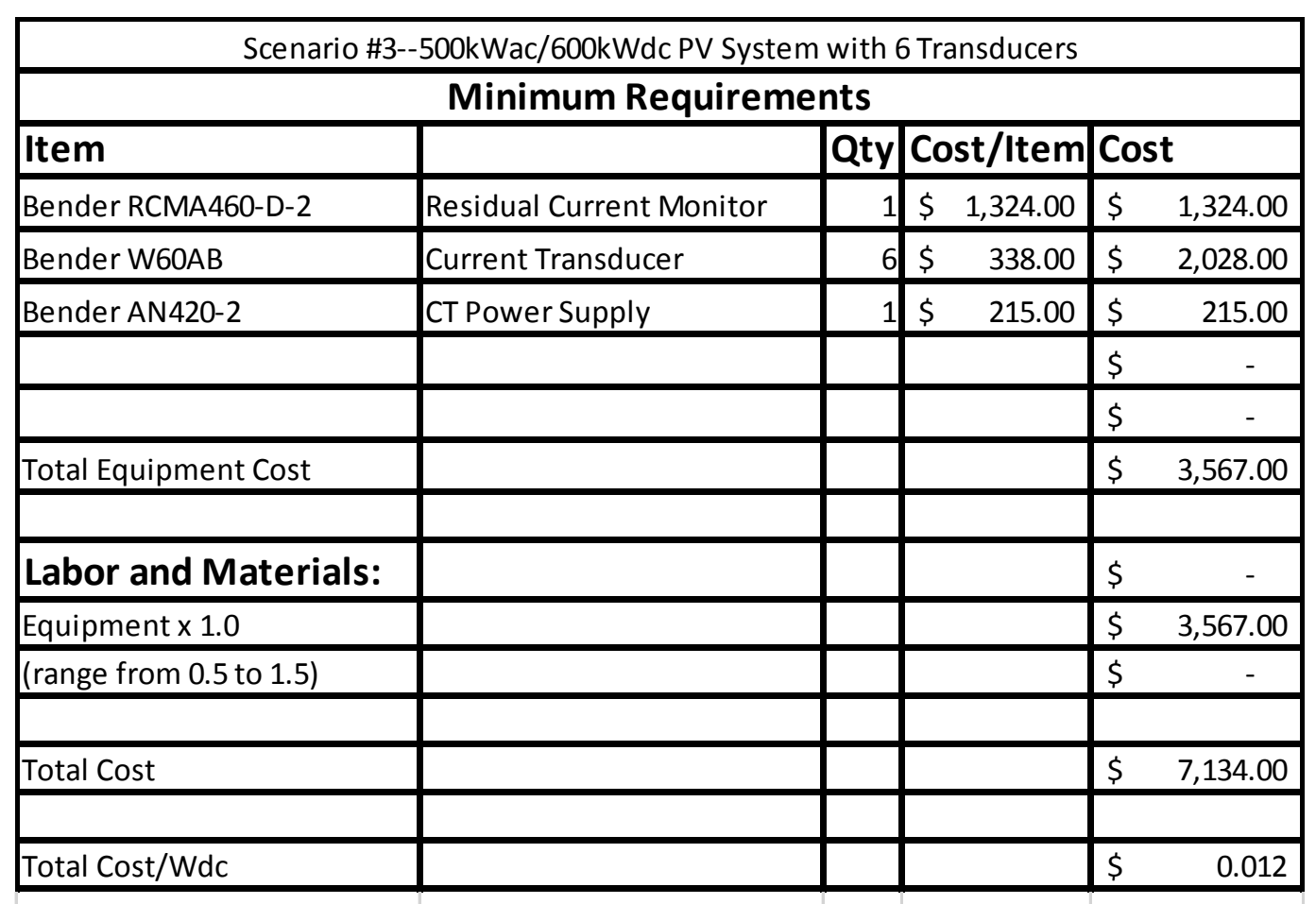

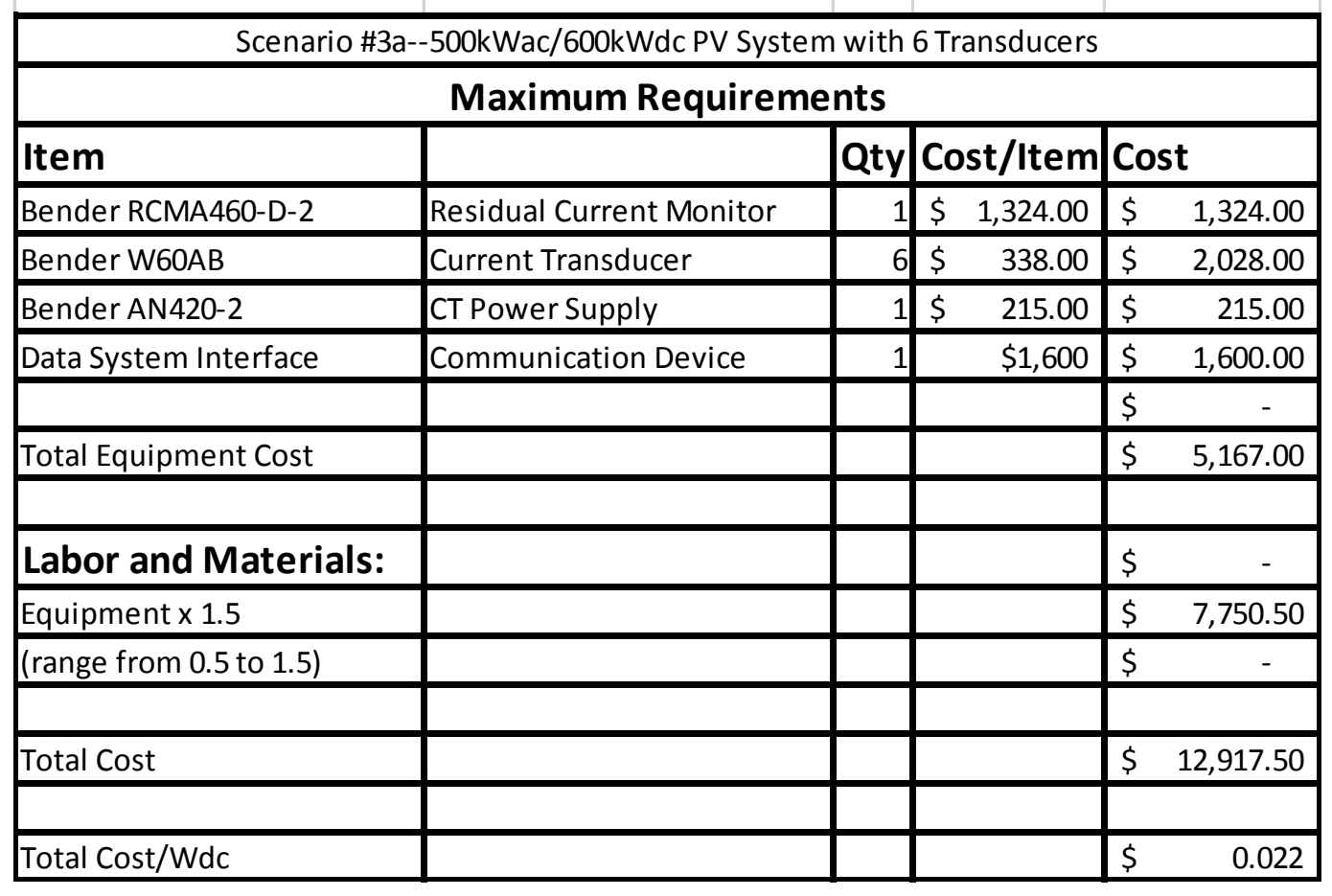




\begin{tabular}{|c|c|c|c|c|c|}
\hline \multicolumn{6}{|c|}{ Minimum Requirements } \\
\hline Item & Description & Qty & Cost/Item & Co & \\
\hline Bender RCMA423-D-2 & Residual Current Monitor & 1 & $\$ \quad 527.00$ & $\$$ & 527.00 \\
\hline \multirow[t]{4}{*}{ Bender W120AB } & Current Transducer & 1 & $\$ \quad 555.00$ & $\$$ & 555.00 \\
\hline & & & & $\$$ & - \\
\hline & & & & $\$$ & - \\
\hline & & & & $\$$ & - \\
\hline Total Equipment Cost & & & & $\$$ & $1,082.00$ \\
\hline Labor and Materials: & & & & $\$$ & - \\
\hline Equipment x 1.0 & & & & $\$$ & $1,082.00$ \\
\hline (range from 0.5 to 1.5 ) & & & & $\$$ & - \\
\hline Total Cost & & & & $\$$ & $2,164.00$ \\
\hline Total Cost/Wdc & & & & $\$$ & 0.007 \\
\hline
\end{tabular}

\begin{tabular}{|l|l|r|rr|l|l|}
\hline \multicolumn{5}{|c|}{ Scenario \#1a--250kWac/300kWdc PV System with 1 Transducer } \\
\hline \multicolumn{5}{|c|}{ Maximum Requirements } \\
\hline Item & \multicolumn{1}{c|}{ Qty } & Cost/Item & Cost \\
\hline Bender RCMA423-D-2 & Residual Current Monitor & 1 & $\$ 527.00$ & $\$$ & 527.00 \\
\hline Bender W120AB & Current Transducer & 1 & $\$ 555.00$ & $\$$ & 555.00 \\
\hline Data System Interface & Communication Device & 1 & $\$ 1,600$ & $\$$ & $1,600.00$ \\
\hline & & & & $\$$ & - \\
\hline & & & & $\$$ & - \\
\hline Total Equipment Cost & & & & $\$$ & $2,682.00$ \\
\hline & & & & & \\
\hline Labor and Materials: & & & & $\$$ & - \\
\hline Equipment x 1.5 & & & & $\$$ & $4,023.00$ \\
\hline (range from 0.5 to 1.5) & & & & $\$$ & - \\
\hline & & & & & \\
\hline Total Cost & & & & $\$$ & $6,705.00$ \\
\hline & & & & & \\
\hline Total Cost/Wdc & & & & $\$$ & 0.022 \\
\hline
\end{tabular}

The cost per dc Watt is computed for scenario 1 with the $250-\mathrm{kW}$ inverter. The lowest cost solution is a single current transducer with a single monitor. If no data system interface equipment is necessary, the total cost of the installation may be as low as $\$ 2,200$, which equates to $\$ 0.007 / \mathrm{kW}$. This configuration may not be possible if all the conductors cannot be routed through a single $120-\mathrm{mm}$ diameter transducer. To bound costs on the upper end, scenario $2 \mathrm{a}$ for 
the $250-\mathrm{kW}$ inverter system includes three current transducers, data system interface hardware, and installation costs on the high end. This results in a higher end cost of $\$ 0.0035 / \mathrm{W}$.

\begin{tabular}{|c|c|c|c|c|c|}
\hline \multicolumn{6}{|c|}{ Scenario \#2--250kWac/300kWdc PV System with 3 Transducers } \\
\hline \multicolumn{6}{|c|}{ Minimum Requirements } \\
\hline Item & & Qty & Cost/Item & Cos & \\
\hline Bender RCMA460-D-2 & Residual Current Monitor & & $\$ 1,324.00$ & $\$$ & $1,324.00$ \\
\hline Bender W60AB & Current Transducer & 3 & $\$ 338.00$ & $\$$ & $1,014.00$ \\
\hline Bender AN420-2 & CT Power Supply & 1 & 215.00 & $\$$ & 215.00 \\
\hline & & & & $\$$ & - \\
\hline & & & & $\$$ & - \\
\hline Total Equipment Cost & & & & $\$$ & $2,553.00$ \\
\hline Labor and Materials: & & & & $\$$ & - \\
\hline Equipment $\times 1.0$ & & & & $\$$ & $2,553.00$ \\
\hline (range from 0.5 to 1.5 ) & & & & $\$$ & - \\
\hline Total Cost & & & & $\$$ & $5,106.00$ \\
\hline Total Cost/Wdc & & & & $\$$ & 0.017 \\
\hline
\end{tabular}

\begin{tabular}{|c|c|c|c|c|c|}
\hline \multicolumn{6}{|c|}{ Scenario \#2a--250kWac/300kWdc PV System with 3 Transducers } \\
\hline \multicolumn{6}{|c|}{ Maximum Requirements } \\
\hline Item & & Qty & Cost/Item & Co & \\
\hline Bender RCMA460-D-2 & Residual Current Monitor & 1 & $\$ 1,324.00$ & $\$$ & $1,324.00$ \\
\hline Bender W60AB & Current Transducer & 3 & $\$ 338.00$ & $\$$ & $1,014.00$ \\
\hline Bender AN420-2 & СТ Power Supply & 1 & 215.00 & $\$$ & 215.00 \\
\hline \multirow[t]{2}{*}{ Data System Interface } & Communication Device & 1 & $\$ 1,600$ & $\$$ & $1,600.00$ \\
\hline & & & & $\$$ & - \\
\hline Total Equipment Cost & & & & $\$$ & $4,153.00$ \\
\hline Labor and Materials: & & & & $\$$ & - \\
\hline Equipment x 1.5 & & & & $\$$ & $6,229.50$ \\
\hline (range from 0.5 to 1.5$)$ & & & & $\$$ & - \\
\hline & & & & & \\
\hline Total Cost & & & & $\$$ & $10,382.50$ \\
\hline Total Cost/Wdc & & & & $\$$ & 0.035 \\
\hline
\end{tabular}




\begin{tabular}{|c|c|c|c|c|c|}
\hline \multicolumn{6}{|c|}{ Scenario \#1--100kWac/125kWdc PV System with 1 Transducer } \\
\hline \multicolumn{6}{|c|}{ Minimum Requirements } \\
\hline Item & Description & Qty & Cost/Item & Co: & \\
\hline Bender RCMA423-D-2 & Residual Current Monitor & 1 & 527.00 & $\$$ & 527.00 \\
\hline Bender W60AB & Current Transducer & 1 & 338.00 & $\$$ & 338.00 \\
\hline & & & & $\$$ & - \\
\hline & & & & $\$$ & - \\
\hline & & & & $\$$ & - \\
\hline Total Equipment Cost & & & & $\$$ & 865.00 \\
\hline & & & & & \\
\hline Labor and Materials: & & & & $\$$ & - \\
\hline Equipment x 1.0 & & & & $\$$ & 865.00 \\
\hline (range from 0.5 to 1.5 ) & & & & $\$$ & - \\
\hline & & & & & \\
\hline Total Cost & & & & $\$$ & $1,730.00$ \\
\hline Total Cost/Wdc & & & & $\$$ & 0.014 \\
\hline
\end{tabular}

\begin{tabular}{|c|c|c|c|c|c|}
\hline \multicolumn{6}{|c|}{ Scenario \#1a--100kWac/125kWdc PV System with 1 Transducer } \\
\hline \multicolumn{6}{|c|}{ Maximum Requirements } \\
\hline Item & & Qty & Cost/Item & Co & \\
\hline Bender RCMA423-D-2 & Residual Current Monitor & 1 & 527.00 & $\$$ & 527.00 \\
\hline Bender W60AB & Current Transducer & 1 & $\$ \quad 338.00$ & $\$$ & 338.00 \\
\hline Data System Interface & Communication Device & 1 & $\$ 1,600$ & $\$$ & $1,600.00$ \\
\hline & & & & $\$$ & - \\
\hline & & & & $\$$ & - \\
\hline Total Equipment Cost & & & & $\$$ & $2,465.00$ \\
\hline & & & & & \\
\hline Labor and Materials: & & & & $\$$ & - \\
\hline Equipment x 1.5 & & & & $\$$ & $3,697.50$ \\
\hline (range from 0.5 to 1.5 ) & & & & $\$$ & \\
\hline Total Cost & & & & $\$$ & $6,162.50$ \\
\hline & & & & & \\
\hline Total Cost/Wdc & & & & $\$$ & 0.049 \\
\hline
\end{tabular}

The cost per dc Watt for scenario 1 with the $100-\mathrm{kW}$ inverter. The lowest cost solution is a single current transducer with a single monitor. If no data system interface equipment is necessary, the total cost of the installation may be as low as $\$ 1,750$, which equates to $\$ 0.014 / \mathrm{kW}$. This configuration may not be possible if all the conductors cannot be routed through a single $60-\mathrm{mm}$ diameter transducer. To bound costs on the upper end, scenario $1 \mathrm{a}$ for the $500-\mathrm{kW}$ inverter system still includes one current transducer, data system interface hardware, and installation costs on the high end. This results in a higher end cost of $\$ 0.049 / \mathrm{W}$. To summarize, the cost of implementing high-resolution RCMs into PV systems of 500- to $100-\mathrm{kW}$ inverter size is approximately $\$ 0.004 / \mathrm{kWdc}$ to $\$ 0.049 / \mathrm{kWdc}$. 